Portland State University

PDXScholar

7-1979

\title{
Closedmindedness as a Predictor of Individual Decision-Making Behaviors
}

Annette I. Jolin

Portland State University

Follow this and additional works at: https://pdxscholar.library.pdx.edu/open_access_etds

Part of the Personality and Social Contexts Commons, and the Social Psychology Commons Let us know how access to this document benefits you.

Recommended Citation

Jolin, Annette I., "Closedmindedness as a Predictor of Individual Decision-Making Behaviors" (1979). Dissertations and Theses. Paper 2903.

https://doi.org/10.15760/etd.2899

This Thesis is brought to you for free and open access. It has been accepted for inclusion in Dissertations and Theses by an authorized administrator of PDXScholar. Please contact us if we can make this document more accessible: pdxscholar@pdx.edu. 
AN ABSTRACT OF THE THESIS OF Annette I. Jolin for the Master of Science in Psychology presented July 27, 1979.

Title: Closedmindedness as a Predictor of Individual Decision-Making Behaviors.

APPROVED BY MEMBERS OF THE THESIS COMMITTEE:

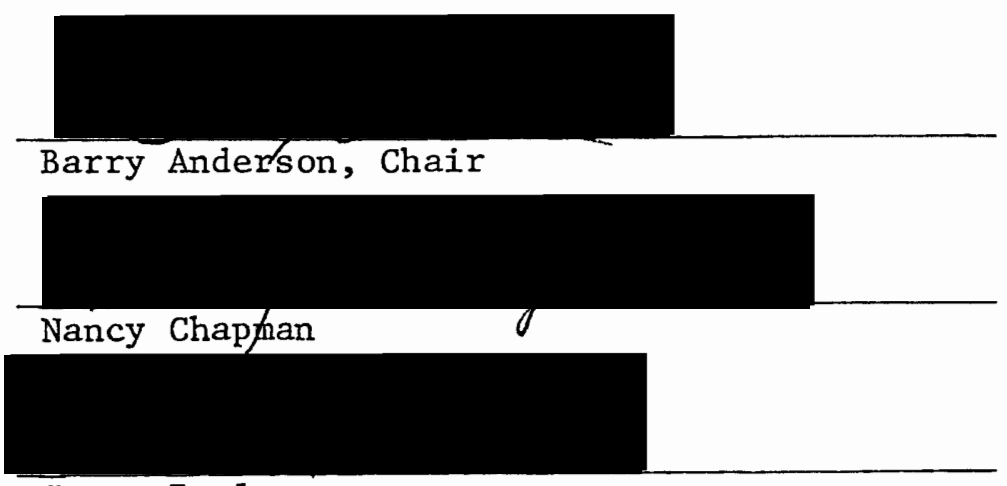

$$
\text { James Paulson }
$$

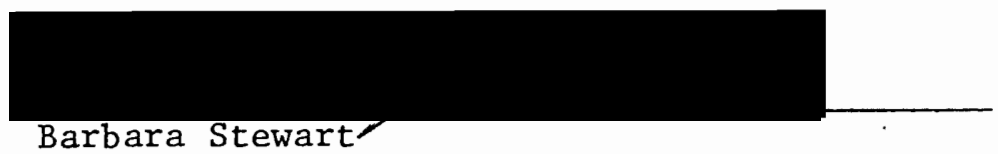

The purpose of this study was to examine whether closedmindedness is related to decision-making behaviors. The decision-making variables in this study were: Pieces of Information, Decision Change, Decision Confidence, Decision Accuracy and, post hoc, Decision Appropriateness. The measures of decision-making behaviors were obtained from four decision situations developed by the experimenter. Closedmindedness was assessed using Rokeach's (1960) Dogmatism (D) scale.

Persons with high D-scores tended to arrive at decisions on the basis of less information than persons with low $D-s c o r e s ~(r=-.22, p<.05)$ and to make more appropriate use of information $(r=+.40, p<.01)$, yet they showed no tendency to differ in either accuracy $(r=+.06, p>.05)$ 
or confidence $(\mathrm{r}=-.18, \mathrm{p}>.05)$. Furthermore, they showed no tendency to be less able to reverse an earlier decision $(r=+.04, \mathrm{p}>.05)$.

Two interpretations, one in terms of intelligence and one in terms of dogmatism, are presented. 
CLOSEDMINDEDNESS AS A PREDICTOR OF INDIVIDUAL

DECISION-MAKING BEHAVIORS

by

ANNETTE I. JOLIN

A thesis submitted in partial fulfillment of the requirements for the degree of

MASTER OF SCIENCE

in

PSYCHOLOGY

Portland State University

1979 
TO THE OFFICE OF GRADUATE STUDIES AND RESEARCH:

The members of the Committee approve the thesis of Annette I. Jolin presented July 27, 1979
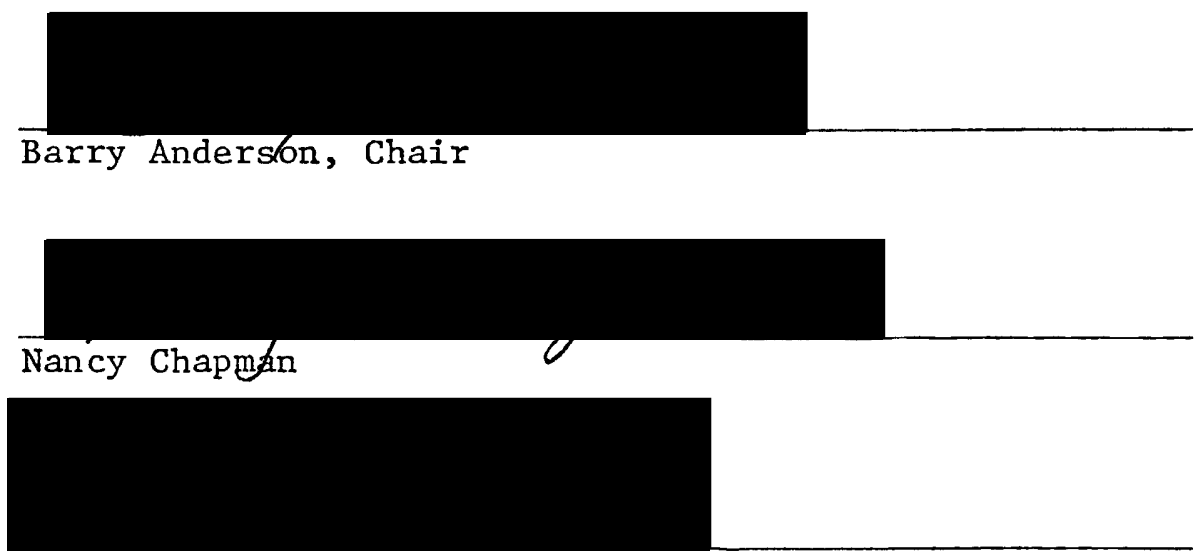

James Paulson

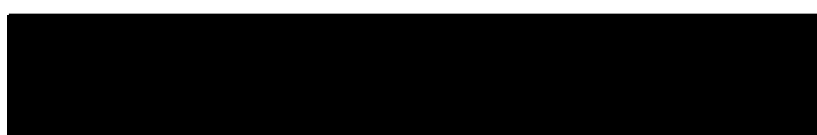

Barbara Stewart

APPROVED:

Robert E. Jones, Hegl, 'Department of Psychology

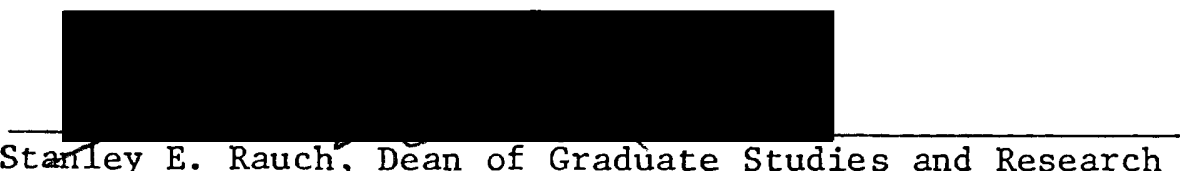




\section{ACKNOWLEDGEMENTS}

I want to thank Barry Anderson for his enthusiastic support, his many valuable ideas, his patient advice and the many hours he contributed; Jim Paulson for his thoughtful examination of the data; Barbara Stewart for the professional and personal understanding she showed; Nancy Chapman for her interest and willingness to be involved in this project.

For unending patience, support and understanding, I thank especially Jim and my children, Marc and Andrea. My great appreciation goes to Bethel Richardson for her careful examination of the manuscript. 
CHAPTER

I INTRODUCTION . . . . . . . . . . . . I

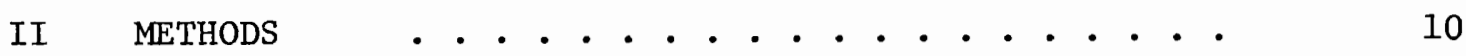

Subjects . . . . . . . . . . 10

Procedure .............. . . . 10

Design ................... 15

III RESULTS . . . . . . . . . . . 17

Part 1: Relationship between Predictor and Criterion variables .........

Part 2: Predictor and Criterion variables considered separately .........

IV DISCUSSION ..............

TABLES

REFERENCES 


\section{LIST OF TABLES}

TABLE

PAGE

1 Comparison Figures (Correlations) Between Results

of This Study and Those of Other Authors'

Correlations Between Dogmatism and Pieces

of Information etc. . . . . . . . . . . .

2 Correlations Between Independent and Dependent

Variables . . . . . . . . . . . . . .

3 Results of a Test for Significance Between

Criterion Correlations . . . . . . . . . .

4 Decision Task Characteristics (Correlations . . .

5 Correlations Between Diagnosticity and Decision

Variables . . . . . . . . . . . . .

Distributional Statistics for Predictor and

Criterion Variables . . . . . . . . . . . 


\section{CHAPTER I}

\section{INTRODUCTION}

Individual differences are readily apparent not only in the quality of a decision but also in decision-making behaviors. Variations in -. decision-making behaviors are attributable, at least in part, to the individual's emotional make-up and the relationship of the emotional make-up to the individual's cognitive structure. Frenke1-Brunswick (1949) is prominent among the many who have pointed to this relationship between personality and cognitive variables. She found that variations in parental behavior result in variations in the child's ability to tolerate ambiguity. According to Vacchiano et al. (1969), later studies have supported this view.

One personality dimension that has been linked widely with cognitive functioning is dogmatism, or closedmindedness. Rokeach (1954) defines closedmindedness "(a) a relatively closed cognitive organisation of beliefs and disbeliefs about reality, (b) organized around a central set of beliefs about absolute authority which in turn, (c) provides a framework for patterns of intolerance toward others" (p. 195). Rokeach's measure of closedmindedness is dogmatism (D-scale). Allport (1947) observed, many years ago, that whether or not facts are ignored or falsified is the result of both intellectual and emotional forces existing in the individual. Ignoring or falsifying facts on the basis of value structures present in the individual has the potential effect of warding 
off threats from reality (Allport, 1947). At the same time, according to Maslow (1954), it gives the individual the feeling of understanding reality. Thus, closedmindedness has come to be seen as a cognitive defense mechanism. One would expect it to discriminate individual decision-making behaviors.

This study focuses on two pre-decisional and two post-decisional aspects of decision-making behavior. The pre-decisional behaviors measured are Pieces of Information Sought and Decision Change. The postdecisional behaviors examined are Decision Confidence and Decision Accuracy. Several studies have examined these aspects of decisionmaking. (See Table 1 for a summary comparison of selected findings.). Pruitt (1961) specifically focused on how many pieces of information were requested by an individual prior to making a decision. His subjects were asked to decide whether a red or a green light was more likely to flash. Information consisted of a sequence of flashes of these lights. Under one condition, a subject could make this decision only once per sequence, whereas under another condition, prior to seeing any lights, an initial decision had to be made, but this decision could later be changed once. Using the expected-value model of decision-making, Pruitt calculated the expected value for both conditions, which was assumed to represent a rational strategy for making a decision. The results he obtained indicated that more information was needed to change a decision than to make an initial decision. He was able to discriminate readily among his subjects with respect to the number of pieces of information they required. However, he did not link these differences to any personality variables.

Feger (1978) also discriminated reliably among subjects on the basis 
of their choice of pre-decisional stopping points (p. 336). Again, this finding was not linked to any personality variables.

Long and Ziller (1965) did link pre-decisional information search to closedmindedness, specifically, to Rokeach's D-scale. They theorized, as did Rokeach (1960), that high D-scale individuals would be closed to new information. The expected negative relationship between $\mathrm{D}$-scale and Pieces of Information Sought was found for each of the tasks, the Pearson product-moment correlation coefficients being -.20, -.24, -.28, 0.32 (see Table 1). The sample Long and Ziller studied consisted of 79 first-year college women at the University of Delaware. There were four different tasks: a "Word Completion Task," a "Line Judgment Task," a "Concept Formation Task" and a "Withholding Opinion Scale." Long and Ziller (1965) concluded:

The negative relationship between Rokeach's Dogmatism scale and the four decision measures supports the initial hypothesis and indicates that in decision-making situations the non-dogmatic person tends to delay decision or reserve judgment, and to search for and utilize additional information. (p. 377)

In a presentation to the 80th Annual American Psychological Association Convention, Taylor (1972) reported results which suggested that high D-scale individuals tend to be more confident of their decisions and to make more accurate decisions. Taylor was not able to obtain a significant negative correlation between closedmindedness $D$-scale and either Amount of Information or Decision Flexibility. His 79 subjects represented a wide range of line management levels from foremen to factory managers, and decision-making behaviors were assessed via the Personnel Decision Simulation (PDS) scale, which requires the subject to make a promotion decision. This instrument yields scores for, inter alia: 
Amount of Information, Decision Accuracy, Decision Confidence and Decision Flexibility. Correlation coefficients were obtained for D-scale and each of the above-listed variables. For Decision Confidence an $\underline{x}=+.27$ was obtained, for Decision Accuracy the $\underline{x}=+.23$, both correlations significant at the .05 level. The Amount of Information/D-scale correlation of -.17 as well as the Decision Flexibility/D-scale correlation of -.10 were found to be in the expected direction, but were not significant.

In a later study, Taylor and Dunnette (1974) again obtained nonsignificant negative correlations between D-scale and Amount of Information and between $\mathrm{D}-\mathrm{scale}$ and Decision Flexibility, the direction in both cases being negative. The subjects and the design of this study were essentially the same as in the earlier study conducted by Taylor in 1972 . The Personnel Decision Simulation instrument yielded scores for Amount of Information which correlated with $\mathrm{D}$-scale $-.16, \mathrm{p}>.05$; Decision Accuracy +.23, $\mathrm{p}<.05$; Decision Confidence $+.27, \mathrm{p}<.05$; Decision Flexibility $-.09, \mathrm{p}>.05$ (see Table 1).

The findings reported thus far fail to give clear support to the existence of a relationship between closedmindedness and any of the variables under examination. Though all correlations between closedmindedness and Amount of Information have been negative, none since the Long and Ziller study has been significant. It is hoped that the present study will clarify this relationship and also those between D-scale, Decision Change, Decision Confidence and Decision Accuracy.

Several measures of open- and closedmindedness have been proposed: Rokeach's Dogmatism (D-scale), Korn and Giddan's Dogmatism (P-scale), 
and Wilson and Patterson's Conservatism (C-scale). Rokeach's (1956) D-scale is designed to measure "the extent to which a person can receive, evaluate and act on relevant information on its own intrinsic merits, unencumbered by irrelevant factors in the situation arising from within the person or from the outside" (p. 57). Rokeach (1960, pp. 89-90) reported reliability figures for $\mathrm{D}$-scale that ranged from .68 to .93 for time intervals of from one to six months. Ehrlich (1961), in a five-year test/re-test follow-up study, reported reliability coefficients of .55. A later study by Zagona and Zurchner (1965) essentially substantiated Rokeach's and Ehrlich's earlier findings.

Several researchers have undertaken validity studies of the D-scale. Plant (1960), in a replication of Rokeach's own concurrent validation study, substantiated Rokeach's findings that the D-scale was less loaded with ethnocentrism than the Authoritarianism F-scale and therefore constituted a better measure than the F-scale. Vacchiano, Schiffman and Strauss (1967) performed three independent factor analyses of the D-scale items and found that the scale contained several factors and could not be reduced to one dimension. (Unfortunately, it was not possible to examine these factors separately in the present study because the method of scoring was not reported.) The analysis of items produced factors that "tended to group around Rokeach's theoretical definition" (p. 847).

The authors reported nine significant factors, some of the strongest among those being: Factor I, which consisted of those items that reflected the subjects' strong desire for group cohesiveness and intolerance of the deviant; Factor II, which consisted of items that indicated the subjects' 
negative assessment of people who hold beliefs contrary to their own; Factor III, whose items reflected importance attributed to a mission or great cause in Iife; and Factor V, which was composed of items that addressed the subjects' insecurity and anxiety over inadequacy and dependence on authority (pp. 849-51). Reliability figures for these factors were not provided by the authors. Their sample consisted of 88 women and 87 men.

Korn and Giddan (1964), in another construct validity study, examined the relationship between the D-scale and several of the California Psychological Inventory scales. The results confirmed the negative correlations with Flexibility, Tolerance and Well-Being which were predicted by Rokeach's broad definition of what the D-scale measures.

White and Alter (1966) reported norms for the D-scale, based upon 37 samples from various populations. They found generally wide variations in means, which led them to caution that the D-scale might be highly sensitive to subcultural differences, particularly since the most extreme means were found in non-college student samples. In addition, Alter and White (1966), Korn and Giddan (1964), and Vacchiano, Schiffman and Strauss (1967) found that women scored consistently lower than men. The most consistent criticism brought against the D-scale addresses the issue of an agreement response set. Several researchers (Couch \& Keniston, 1960; Lichtenstein, Quinn \& Hover, 1961; Peabody, 1961, 1966) found that at least some agreement component entered into D-scale performance. Korn and Giddan (1964), who based their study on Peabody's (1961) concepts, showed that most of the variance accounted for by the total score could be accounted for by the direction of the response. They 
suggested the use of what they called "P-score," rather than Rokeach's composite score. The "P" stands for "Proportion" and is defined as "The mean extremeness in the positive direction" (p. 868). The P-score merely gives the frequency of agree responses whereas the composite score reflects the intensity, as well as the direction, of the response to an item. The P-score was found to account for 90 percent of the variance in the composite score. The authors had expected that a person who generally gives an extreme agreement response (high dogmatic), would choose a moderate or low disagreement response whenever he or she would not agree with an item. This should then have resulted in a negative relationship between dichotomous extreme responses (p. 870). Their results, however, failed to support this hypothesis, and instead indicated that a person who indicates agreement with D-scale items in an extreme manner also tends to indicate disagreement in an extreme manner. The authors interpret this finding to indicate the operation of an extremeness response set. (p. 870). They continue to reason that "since $\underline{\mathrm{P}}$ is a good approximation of $\underline{\mathrm{C}}$ and eliminates a possible extremeness response set, we shall now use the $\underline{p}$ score. . ." (p. 871). For the purposes of the present study, both a composite score and an agreement (P) score were determined.

In 1968, Wilson and Patterson (1968), in answer to the response set problems encountered by agreement scales such as the D-scale, developed a Conservatism scale (C-scale). The C-scale was designed to differ from other scales in that "the basic formula ' $\mathrm{X}$ is a good/bad thing' (agree or disagree) is substituted by the simple formula, 'X' (good or bad)" (p. 50). Wilson and Patterson (1968) hypothesized, "Because the item 
is reduced to attitude content or referent alone, we might expect that contamination due to context (grammatical confusion, ambiguity, task conflict, acquiescence, etc.) will be brought to a minimum" (p. 50). They claim that the scale is predominantly uni-dimensional. Reliability figures from several studies (Nias, et al., 1971; Wilson \& Patterson, 1969; Schneider \& Minkmar, 1972 as cited by Wilson \& Patterson, 1973) give coefficients that range from .89 to .94 . Construct validity, the authors indicated, is partially established in that their theoretical expectation that conservatism increases with age and is slightly higher with females was supported by their data. (In contrast, women were found to score consistently lower on the D-scale.) "Known group" validation studies (Wilson \& Patterson, 1968; Wilson \& Lillie, 1972, as cited by Wilson, 1973) have shown the extreme group scores to be satisfactorily separated on the test. Concurrent validity was measured by correlating C-scale scores with the California F-scale $(\underline{r}=+.68)$ and Rokeach's D-scale $(\underline{r}=.39$.

The normative information provided by Wilson and Patterson (1968) shows great variation in means between different groups of people, with university students on the lower end of conservatism and parents of university students and housewives on the upper end. It should be noted that reliability, validity, and normative figures for this scale are based on studies conducted in Great Britain, The Netherlands, West Germany, New Zealand and the United States.

The C-scale will be used in the present study, in addition to Rokeach's D-scale, although it is recognized that different theoretical bases exist for these measures. 
The four major hypotheses under examination in the present study are based upon the earlier cited research findings provided by Long and Ziller (1965), Pruitt (1961), Taylor (1972) and Taylor and Dunnette (1974), as well as the theoretical positions adopted by Rokeach (1960) and retained in somewhat altered form by Janis and Mann (1977). Hypothesis I postulates that Closedmindedness as a cognitive defense mechanism results in the more closedminded person's use of fewer Pieces of Information.

Hypothesis II, in accordance with theoretical (Rokeach, 1960; Wilson, 1973) and empirical (Ehrlich \& Lee, 1969; White \& Alter, 1965) findings, postulates that Decision Flexibility or Decision Change, measured by the number of times a preliminary decision is changed prior to the final decision, correlates negatively with high scores on the D-scale. Hypothesis III deals with the individual's confidence estimate of the probability of correctness of the final decision. Studies by Taylor (1972) and Taylor and Dunnette (1974) show that persons scoring high on the D-scale tend to be more confident of the correctness of the decisions they have made. It is therefore expected that $\mathrm{D}$-score correlates positively with Decision Confidence.

Hypothesis IV concerns Decision Accuracy. Taylor \& Dunnette (1974) found some indication that D-score correlates positively with Decision Accuracy. A tentative hypothesis will be made that D-score correlates positively with Decision Accuracy. 


\section{CHAPTER II}

\section{METHODS}

\section{Subjects}

A total of 38 women and 35 men participated in this study. All were students recruited from sociology, criminal justice, and psychology classes at the community college and university levels. Ages ranged from 15 to 49 years, with a mean of 25 years (see Table 3). The participation of subjects in this study had been approved by the Human Subjects Committee at Portland State University.

\section{$\underline{\text { Procedure }}$}

Each subject was issued a numbered folder which contained, in this order: two personality measures, the Dogmatism Scale (from which D-scale scores and pracke scores would be computed) and the Conservatism Scale (C-scale); one' sheet containing written instructions for the decision situations and providing space for the subjects to record their age and sex; decision situation $\mathrm{F}$; and finally, in a randomized order, the remaining three decision situations, B, C, F and S.

Before the subjects opened the folders, the experimenter made a statement which covered the following points:

-The entire experiment consists of six parts.

-Please complete part one and two and then wait for additional verbal instructions before you proceed.

-Do not change the order in which the tasks appear in front of you. 
-Each of you will be working on different decision situations with different solutions.

-During the time that you are working on decision situation $F$, which is the first decision situation for each of you, you may ask questions regarding the procedure for completing that task. -After you have completed decision situation $F$ and have proceeded to the next decision situation, it will be assumed that you know what to do, and the experimenter will no longer be able to answer questions.

-Please read all the instructions carefully and follow them in a step-by-step fashion.

The participants first completed the D-scale form E, which consisted of 40 statements (e.g., "It is only natural for a person to be rather fearful of the future.") Subjects were asked to indicate agreement or disagreement with each statement along $a+3$ to -3 scale with no zero point. These scores were later converted into a 1 to 7 scale by adding a constant of 4 to each score. This makes possible scores $1,2,3,5,6$, and 7 with no 4. This scoring method was developed by Rokeach and is suggested for use in the test's manual. Scores can range from 40 to 280 with a high score indicative of a high degree of dogmatism. Because several subjects who had participated in a pilot study for this experiment had expressed strong negative reactions to the 1960s "sexist" wording of some of the items, it was decided to change the word "man," wherever it was used to refer to both men and women, to "person." For example, item 37: "A man who does not believe in some great cause has not really lived," was changed to read: "A person who does not believe in some 
great cause has not really lived." (For a complete list of the changed items see Appendix B).

As indicated earlier, Dogmatism P-scores were obtained as well. Secondly, subjects completed the 50-item C-scale developed by Wilson and Patterson (1968). Items consisted of one or two words (e.g., "birth control") to which the subject was to say "Yes," "?" or "No." of the 50 items, the odd numbered items require "Yes" responses, to be scored as indicators of conservatism and the even numbered items require "No" responses to be scored as indicators of conservatism. Instructions are brief and in written form at the top of the single-page instrument. A liberal response was scored as zero; an ambiguous (?) response, as 1; and a conservative response as 2 . Scores can range from 0 to 100 , with the higher scores indicative of conservatism.

Thirdly, subjects proceeded to a coversheet asking them to provide demographic information such as Age and Sex. This was followed by written instructions pertaining to the decision tasks. (For detail see Appendix A).

Each situation began with a description of the setting, for example, "You are a buyer for a large department store. . . ." (See Appendix A). Two conditions are developed in the subsequent "story." Each condition represents a set of given odds such as "the manufacturer produces a slightly defective shoe . . about $20 \%$ of the time. The other manufacturer produces such a shoe about $40 \%$ of the time." The "story" then sets the scene for the prospective decision-maker to have an opportunity to look at a given number of randomly selected samples prior to making the decision. A cost factor is associated with looking at each additional sample (piece of information). Three samples are available 
at the outset. From then on samples can be obtained by removing small round labels one at a time up to a total of ten.

The "story" then brings the subject to the point where it must be decided whether the samples available for inspection up to this point are likely to represent the "20\% or $40 \%$ defective shipment." A cost factor is associated with decision accuracy as well. Gains and losses are balanced in each situation.

As noted, each subject has the opportunity at the beginning of each decision section, to make a decision on the basis of three pieces of information which are provided "free of cost." If, for example, an acceptable shoe is represented by the symbol " + " and an unacceptable shoe by the symbol "-," this initial information might be represented as "++-." The subject is then asked Question 1, whether the three samples are more likely to have come from the $20 \%$ or the $40 \%$ defective shipment? This decision is followed by the request to indicate on a scale with a probability range .5 (uncertain) to 1.00 (completely certain), how certain he or she is about the decision just made. Question 2 asks the subject to decide whether he or she wants more information. If so, a box can be checked which indicates that the above decision constitutes a preliminary decision and the subject is directed to inspect the next sample which up to now has been covered by a small round label. The removal of this label makes a total of four samples available for inspection, e.g., "++-+." Question 3 asks the subject whether the decision he or she made is a final decision, and applies only to subjects who do not want additional information. The subject, by checking a box, indicates that the decision made on question 1 represents a final decision and is 
subsequently directed to go on to the next decision situation.

Questions 1, 2, and 3 are repeated for each additional piece of information the subject uncovers. After ten pieces of information, a subject can still indicate a further need for information by checking an appropriate box; however, no additional information can actually be requested or obtained. The maximum number of pieces of information any one subject could obtain in all four situations is 40 .

The time subjects used to complete, all of the tasks ranged from 35 to 65 minutes.

Pieces of Information refers to the number of pieces of information requested by the subject prior to making a final decision. Decision Change indicates how many times a subject changed his or her decision prior to coming to a final decision. Decision Confidence reflects how certain the subject said he or she was about the accuracy of the decision just made. And Decision Accuracy reflects the correctness or incorrectness of the subject's final choice.

These variables were measured via four decision situations developed by the experimenter. All four situations were designed after the bookbag-and-pokerchip paradigm of Edwards (1969). In this paradigm, a subject might be told that there are two bags each containing some blue and some red pokerchips. In one bag the ratio of blue to red chips is 7 to 3 ; in the other bag the ratio is 3 to 7 . Several chips are randomly drawn from one of the two bags, and the subject decides, based upon this information from which bag these chips came. This paradigm permits the calculation of probabilities associated with each piece of information given to or requested by a subject. It also permits the calculation of the 
appropriateness of a decision given the information the subject has obtained.

The basic book-bag-and-pokerchip structure was imbedded into simulated "real life" situations to give the otherwise somewhat artificial task a more realistic flavor. In addition, each situation was written to include a potential pay-off or loss to the subject. Again, this was done to increase realism and subject involvement. (See Appendix A for complete descriptions of each of the four decision situations.)

$\underline{\text { Design }}$

Each of the four situations was designed to contain ten Pieces of Information. Information sequences were generated randomly for each of the 74 subjects in each of the four situations, so that statistically significant results could be generalized across both sequences and subjects.

of the four decision situations, Situation $F$ was the first one each subject completed. The presentation order for the three remaining decision situations was randomized.

The following criteria were used in determining whether the data generated by any given subject should be included in the final data analysis:

-Answers to all 40 questions on the Dogmatism scale, Form E, must have been clearly indicated by the subject. A maximum of two missing responses wias permitted on the questionnaire. The experimenter calculated the subjects' average item response and used the resulting values to replace the missing responses when only one or two were missing. None of the subjects had to be eliminated on the basis of this criterion alone.

-The Conservatism scale must have been completed, and the answers 
clearly marked. In their test manual, the authors of this measure made provisions for missing responses. In accordance with this method, the constant 1 was entered for each missing response. No subjects were eliminated on the basis of this criterion. -No more than five missing values for either age or sex were to be accepted. Three subjects neglected to indicate their age, in which case the age value was not included in the analysis for these subjects, but all other data for these subjects were included in the analysis. All subjects had indicated their gender. -Each subject must have worked through each of the four decision situations in accordance with the written and verbal instructions given. Subjects who failed to do so on any section of these tasks were excluded from the data analysis. A total of 15 subjects had to be excluded because they failed to meet this criterion. 
CHAPTER III

\section{RESULTS}

This section is divided into two parts. Part 1 contains correlations between predictor and criterion variables pertaining to the major hypotheses. Part 2 contains secondary distributional and correlational information on the predictor variables and distributional and correlational information on the criterion variables.

\section{Part 1: Relationships between Predictor and Criterion variables}

The data were subjected to a correlational analysis. The major predictor variable was the $\mathrm{D}$-score. The $\mathrm{P}$ - and $\mathrm{C}$-scores were examined only for their consistency with the D-score. In addition, Age and Sex were also used as predictors. The criterion variables were the decisionmaking variables Pieces of Information Sought, Decision Change, Decision Confidence and Decision Accuracy. Each hypothesis was tested at the .05 level, using a non-directional test.

The major tests of the hypotheses and their results (also presented in Table 2) are as follows:

Across situations, the D-score correlated negatively with Pieces of Information ( $\underline{r}=-.22, \underline{p}<.05$, $\underline{\mathrm{d} f}-72)$, but did not correlate with Decision Change $(\underline{r}=+.04, \underline{p}>.05, \underline{\mathrm{d} f}=72)$, Confidence $(\underline{r}=-.18, \underline{p}>.05$, $\underline{\mathrm{d} f}=72)$ or Accuracy $(\underline{\mathrm{r}}=+.06, \underline{\mathrm{p}}>.05, \underline{\mathrm{d} f}=72)$. The "across-situations" score for each of the four criterion variables Pieces of Information, Decision Change, Confidence and Accuracy was obtained by summing each of 
the four criterion variable scores for each subject over the four situations. The following sections will examine these findings in detail.

Pieces of Information. According to Hypothesis $\mathrm{I}$, a negative correlation between D-score and Pieces of Information was expected. To protect against an adverse finding, an alternate hypothesis that there is a positive correlation between D-score and Pieces of Information was considered. Consequently, the statistical hypothesis was that there is no correlation ..between D-score and Pieces of Information, The level of confidence was set at .05 .

The experimental hypothesis was supported by the data. The correlation of -.22 between D-score and Pieces of Information across situations was weak but statistically significant $(p<.05$, $\underline{d f}=72)$. Correlations for the individual decision situations $F, C, B$ and $S$ were in the same direction but only one of them was significant: Situation $\mathrm{F}: \underline{\mathrm{r}}=-.03, \mathrm{p}>.05$, $\underline{\mathrm{df}}=72$; situation $\mathrm{C}: \underline{\mathrm{r}}=-.19, \underline{\mathrm{p}}>.05$, $\underline{\mathrm{df}}=72$; situation $\mathrm{B}: \underline{\mathrm{r}}=-.17$, $\mathrm{p}>.05, \underline{\mathrm{d} f}=72$; and situation $\mathrm{s}: \underline{\mathrm{r}}=-.29, \mathrm{p}<.05, \underline{\mathrm{d} f}=72$. A t-test for the difference among dependent correlations showed no significant differences between correlations in the four situations.

The Dogmatism P-score (agreement score) when correlated with Pieces of Information across situations yielded no significant relationship $(\underline{r}=-.17, \underline{p}>.05, \underline{d f}=72)$. Individual situations showed a statistically significant correlation between the P-score and Pieces of Information in the hypothesized directions only for situation $S(\underline{r}=-.24, \underline{p}<.05$, df $=72)$. The correlations for situations $F, C$ and $B$, all non-significant, were $+.04,-.16$, and -.18 respectively.

No hypothesis had been stated regarding the relationship of C-score 
and Pieces of Information. The data analysis revealed no relationship between these two variables, the $\mathrm{r}=+.01$ across situations.

Decision Change. Hypothesis II predicted that Opinion Change (indicating how many times a person changed his or her opinion prior to the final decision) correlates negatively with D-scale scores. To protect against an adverse finding, an alternate hypothesis that there is a positive correlation between D-score and Decision Change was considered. Consequently, the statistical hypothesis was that there is no correlation between D-score and Decision Change. The level of confidence was set at .05 .

The data did not support the experimental hypothesis. The acrosssituation correlation coefficient was $\underline{r}=+.04(p>.05$, $\underline{\text { df }}=72)$. Coefficients for the individual decision situations, as well, were non-significant, (see Table 2). The same pattern revealed itself for the correlations with the P-score and the C-score.

Decision Confidence. Hypothesis III stated that persons with high D-scale scores will express greater confidence about the correctness of the decision they have made. Again, an alternate hypothesis was that there is a negative correlation between D-score and Decision Confidence. Consequently, the statistical hypothesis was that there is no correlation between D-score and Decision Confidence. The level of confidence was set at .05 .

The across-situation correlation of -.18 between the D-score and Confidence was not significant. For situation S, the D-score/Confidence correlation was $-.29(\mathrm{p}<.01$, df $=72)$. For all other decision'situations, the D-score failed to correlate significantly with Confidence (see Table 2). Contrary to this hypothesis, however, P-score correlations with 
Confidence were $\underline{r}=-.24(\underline{p}<.05, \underline{\mathrm{d} f}=72)$ across situations and for situation $S$ the $\underline{r}=-.35(\underline{Q}<.01$, $\underline{\mathrm{d} f}=72)$. The correlations for situations F, C and B were in the same direction but not significant (see Table 2).

The C-score did not correlate significantly with confidence in any of the four situations or with the across-situation measure of confidence, which had an $\underline{\underline{r}}=-.15(\mathrm{p}>.05$, $\underline{\mathrm{df}}=72)$ (see Table 2).

Decision Accuracy. Hypothesis IV țentatively postulated a positive relationship between D-score and Decision Accuracy. An alternate hypothesis was'that there is a negative correlation between D-score and Decision Accuracy. Consequently, the statistical hypothesis was that there is no correlation between D-score and Decision Accuracy. The level of confidence was set at .05 .

The results of the data analysis did not support the experimental hypothesis. D-score and Decision Accuracy had an $\underline{r}=+.06(p>.05$, $\underline{\mathrm{d} f}=72)$ across situations. The same nonsignificant pattern occurred for the individual situations (see Table 2).

The P-score and across-situations Accuracy had an $\underline{r}=+.01(p>.05$, $\underline{\mathrm{df}}=72$ ), and again the individual situations showed no relationship (see Table 2).

The C-score did not correlate with Accuracy on either the acrosssituation measure $(\underline{r}=+.16, \underline{p}>.05, \underline{d f}=72)$ or any of the individual situations (see Table 2).

A test of the difference between related correlations indicated no significant differences among the four situations with respect to the relationships between $\mathrm{D}$-score and Pieces of Information, Decision Change, 
Confidence, or Accuracy (see Table 3).

Sex and Age. The predictor variables Sex and Age correlated with none of the decision-making behaviors under examination (see Table 2).

Part 2: Predictor and Criterion variables considered separately

The decision-making variables Pieces of Information, Decision Change, Decision Confidence and Decision Accuracy were also examined. of the six possible across-situation correlations only that between Pieces of Information and Decision Change was statistically significant $(\underline{r}=+.38$, $\left.\mathrm{p}^{<.01,} \underline{\mathrm{df}}=72\right)$. Those who requested more information changed their decisions more frequently.

The criterion variables Pieces of Information, Decision Change, Confidence and Accuracy were also examined. For each of the variables Pieces of Information, Decision Change, Confidence and Accuracy all six possible pairwise correlations between the measures in one of the four situations and that in another were examined. For Pieces of Information these correlation coefficients ranged from +.28 to +.75 and were significant, with the exception of the correlation coefficient +.08 between situations $\mathrm{F}$ and S (see Table 4). For Decision Confidence these correlation coefficients ranged from +.28 to +.60 and were significant (see Table 4). For both Pieces of Information and Decision Confidence these results were to be expected.

For Decision Change these correlations showed little consistency in either extent or direction. None was found to be significant (see Table 4). For Accuracy these correlations were all non-significant (see Table 4). The latter two variables, it should be noted, depended upon the individual sequences experimental design which provided for each subject 
individually generated information samples, and non-significant intercorrelation coefficients could therefore be expected.

Since the experimental design called for sequences of pieces of information that were generated individually for each subject from a random numbers table according to a predetermined probability which changed from decision situation to decision situation, a secondary predictor variable emerged from the data analysis. This variable will be referred to as Diagnosticity variable. The term Diagnosticity, as used by Edwards (1969) in his book-bag-and-pokerchip experiments equals the sample frequency of the more frequent color (red or blue) in the population minus the sample frequency of the less frequent color in the population. In this experiment the term is used identically, as a measure of the extent to which the information favors the correct or the incorrect decision. A Diagnosticity value is thus obtained by taking the number of pieces of information in favor of the correct decision and subtracting from it the number of pieces of information in favor of the incorrect decision. Across situations Diagnosticity correlated significantly $+.37(\mathrm{p}<.01$, df $=72)$ wLth Accuracy. Correlations between Accuracy and Diagnosticity varied from situation to situation. Situation F, C, B and S correlated +.34 $(\mathrm{p}<.01, \underline{\mathrm{df}}=72) ;+.61(\mathrm{p}<.001, \underline{\mathrm{df}}=72) ;+.71(\mathrm{p}<.001, \underline{\mathrm{df}}=72) ;$ and $+.72(\mathrm{p}<.001, \underline{\mathrm{df}}=72)$ respectively (see Table 5).

Criterion variable distributive information. On the average subjects sought $3.1(\underline{S D}=1.82, \underline{N}=74)$ pieces of information of a possible 7 per situation. For situation $F$ the mean was $3.73(\underline{S D}=2.66, \underline{N}=74)$; situation $C$ : $2.23(\underline{\mathrm{SD}}=1.91, \underline{\mathrm{N}}=74)$ situation $\mathrm{B}: 2.37(\underline{\mathrm{SD}}=2.22, \underline{\mathrm{N}}=74)$ and situation S: $3.20(\underline{S D}=2.59, \underline{N}=74)$ (see Table 6). 
Thirty-two percent of the subjects did not change their decision at all, $26 \%$ of the subjects changed their decision once and $24 \%$ of the subjects changed their decision twice which yields a cumulative frequency of $82 \%$ of subjects who changed their decision zero, one or two times of a possible 32 times across situations. The average decision change per situation was 1.47 times $(\underline{S D}=1.48, \underline{N}=74)$ (see Table 6). A t-test for differences between independent means showed no statistically significant $(\underline{t}=.21, \underline{p}>.05, \underline{d f}=72)$ difference, between the $D$-scores of subjects who changed their decision at least once and between those subjects who made no decision changes in any of the four situations. On the average, subjects indicated their Confidence level to be between .84 and .89 in each situation (see Table 3). ".50" indicated complete uncertainty and " 1.00 " complete certainty.

Eighty-eight percent of all subjects made two or more of the four decisions correctly. In situation $\mathrm{F}$ : $77 \%$ of the subjects made the correct decision. In situation C: 61\%; in situation B: $76 \%$; and in situation S: $45 \%$

Correlations among Predictor variables. Correlations between the predictor variables $\mathrm{D}$-score, P-score and $\mathrm{C}$-score as we.11 as Age and Sex were obtained.

The correlation between the $\mathrm{D}-$ and $\mathrm{P}$-score was $+.94(\mathrm{p}<.001$, $\mathrm{df}=72)$, between the $\mathrm{D}-$ and $\mathrm{C}-\mathrm{score}+.22(\mathrm{p}<.05, \mathrm{df}=72)$ and the $\mathrm{P}-$ and $\mathrm{C}-\mathrm{score}$ $+.18(\mathrm{p}<.05, \underline{\mathrm{df}}=72)($ see Table 7$)$.

Neither Age nor Sex correlated with the D-score, the P-score or the C-score (see Table 7).

Distribution information pertaining to the predictor variables Dand P-score, the $\mathrm{C}$-score as well as Age and Sex is 1isted in Table 6. 
CHAPTER IV

\section{DISCUSSION}

of the four hypotheses, only Hypothesis I, which predicted a negative relationship between D-score and Pieces of Information, was supported by the across-situations analysis $(\underline{r}=-.22, \underline{p}<.05$, $\underline{\mathrm{d} f}=72)$. No support was found for Hypothesis II, that D-score correlates negatively with Decision Change, measured by how many times or whether or not a person changed his or her mind prior to making a final decision, nor for Hypothesis III, that D-score correlates positvely with confidence about the correctness of decisions. In fact, the across-situation correlation coefficient between D-score and Confidence, -.18 though non-significant, leaned toward a negative relationship, rather than the expected positive relationship. Finally, Hypothesis IV, which postulated a positive relationship between $D$-score and Accuracy and found no support.

\section{Hypothesis I}

The hypothesized negative relationship between $D$-score and Pieces of Information was obtained across situations. This relationship, although weak $(-.22, \mathrm{p}<.05, \underline{\mathrm{df}}=72)$ was statistically significant. Long and Ziller's (1965) findings show the same negative relationship between D-score and Pieces of Information (see Table 7). Taylor's (1972) results confirmed the ngative direction but, with an $\underline{r}=-.16(\mathrm{p}>.05$, $\underline{\mathrm{d} f}=77$ ), failed to be statistically significant. The same results were 
obtained when Taylor and Dunnette (1974) repeated the Taylor (1972) study in a slightly modified form (see Table 6).

The pattern of the D-score/Pieces of Information correlations is consistent in all of the studies examined. Although the correlations are not always statistically significant, the consistant direction of these correlations, taken by itself, does lend support to Rokeach's theoretical contention that closedmindedness as a general cognitive defense mechanism differ entiates persons by the number of Pieces of Information they seek in decision-making situations.

\section{Hypothesis II}

Rokeach's (1960) theoretical construct of closedmindedness suggests that the more closedminded a person is the less flexible this person will be in revising a belief on the basis of new information. Hypothesis II is based on this theoretical contention and predicts that the higher a person's D-score the less often that person will change his or her decision prior to making a final decision. A negative relationship between D-score and Decision Change is thus expected. This study's findings did not lend support to this hypothesis (see Table 2).

The same lack of relationship between D-score and pre-decisional opinion change was reported by Taylor (1972) and Taylor and Dunnette (1974).

Several studies (Korn \& Giddan, 1964; White \& Alter, 1965; Pyron \& Lambert, 1967) report that closedminded persons lack flexibility, are unable to change, are resistant to change and unaccepting of change. However, these relationships were obtained with personality measures rather than behaviors in decision situations and can therefore not be 
used in a direct comparison with the variables examined in this study. Ehrlich and Lee (1969), in a review of the studies addressing closedmindedness and change of belief, found the evidence for the theoretical construct that closedmindedness inhibits change to be sufficiently inconclusive that they proposed an explanation suggesting that "not all of the belief/disbelief systems will be equally open or closed. . . For some systems of belief and disbelief, open- and closedminded persons will not differ in their rates of learning or change" (pp. 258-259). Similarly, Janis and Mann (1977) suggest within the framework of their Conflict Model of decision-making that under conditions of "unconflicted change . . the dominant tendency will be indifference toward both supportive and non-supportive information" (p. 205). Since closedmindedness is seen as a defense mechanism, conditions of no conflict would not call for defensive action. Hence, whether D-score would be related to Decision Change would depend on how threatening the situation was perceived to be. It could possibly be argued, along with Janis and Mann (1977) and Feger (1977), that studies conducted under relatively low-conflict conditions, such as the kind of simulated real life situations used in this experiment, might not provoke measurable defensive decisionmaking behaviors, such as low rates of Decision Change.

In reference to the present study, however, it should also be kept in mind that the Decision Change criterion variable was dually dependent upon the random individual sequences experimental design and the subject determined stopping point, and for this reason may not constitute the best possible measure of this theoretical construct. 
Hypothesis III

Hypothesis III stated that persons with high D-scores will report higher Confidence estimates about the correctness of their decisions. This contention expands upon the view of closedmindedness as a cognitive defense mechanism. Thus, it is hypothesized, when a closedminded person comes to an early closure of a pending decision this decision will also be defended by being confidently held. The results fail to support the hypothesis that closedmindedness and Confidence are positively related. The correlation coefficient $-.18(\mathrm{p}>.05, \underline{\mathrm{df}}=72)$ across situations indicates that no significant relationship exists (see Table 2).

Taylor (1972) and Taylor and Dunnette (1974), however, did obtain significant positive correlations between closedmindedness and Confidence. In both of their studies the correlation coefficient was $+.27(p<.05)$.

The data in this study suggest a picture of a person who scores high on the D-scale as one who, with relatively little information, comes to a final decision which he or she is no more and no less confident of than the person with a lower D-score. A possible explanation for these results is made somewhat complicated because Pieces of Information, due to the combination of the "individual sequences" experimental design and the subject determined stopping point, is not positively correlated with Confidence (see Table 4). It may be that a person who is threatened by new information and tends to come to a decision more quickly than a non-defensive person is nevertheless quite capable of realistically evaluating his or her decision in terms of a probability confidence estimate pertaining to this decision's accuracy. 
A post hoc reformulation of the variable Decision Accuracy into Decision Appropriateness, (which will be discussed in more detail in the following section) yielded a correlation coefficient of +.40 $(\mathrm{p}<.01, \underline{\mathrm{df}}=72)$ with $\mathrm{D}$-score. This suggests that high $\mathrm{D}$-score persons are evaluating the information they have more appropriately than low D-score persons. Therefore, an appropriate evaluation of their Confidence rather than an inflated one, as the Taylor (1972) and Taylor and Dunnette (1974) studies suggest, appears plausible as well. No relationship was found between Confidence and Appropriateness $(\underline{x}=+.07$, $p>.05, \underline{d f}=72)$. The picture that emerges so far depicts the person with a high $\mathrm{D}$-score, in contrast to the person with a low $\mathrm{D}$-score, as a more efficient user of information but no different so far as the decision criteria Decision Change and Confidence are concerned.

\section{Hypothesis IV}

Hypothesis IV predicted that high D-score persons would tend to matce mere accurate decisions than low D-score persons. The basis for this assertion was derived primarily from the results of the Taylor and Dunnette (1974) study in which a statistically significant positive relationship between D-score and Decision Accuracy had been found (see Table 1). It should be noted, however, that when intelligence was partialled out, this correlation ceased to achieve significance $(\underline{r}=+.14, p>.05)$. On the basis of empirical findings reported by Rokeach (1960), one might expect an equivocal finding. Rokeach found high and low D-score persons to be equal in their ability to analyze problems but found them to differ in their ability to synthesize, with high D-score persons being less well able to do so. Rokeach found generally small correlations between an 
individual's ability solve the Denny Doodlebug problem and intelligence. Rokeach addresses the problem solving process rather than the correctness of the outcome. In fact a person's ability to solve the problem correctly is subsumed under the larger concept of a person's ability to synthesize (p. 176). It should be kept in mind that Taylor's promotional decision situation might not be comparable to Rokeach's problem solving task.

The findings obtained from the present study show that, across situations, D-score and Decision Accuracy are not related (see Table 2). Since several factors, as a result of the experimental design, affected the variable Decision Accuracy, a closer look at this variable and what it measures seems appropriate.

As reported earlier, the variable Diagnosticity was highly correlated with Accuracy $\underline{\underline{r}}=+.70, \underline{p}<.001$, $\underline{\mathrm{df}}=72)$ which indicates that, when a subject did have "good" information, the likelihood of a correct decision was considerably greater than chance. Diagnosticity, however, variea from situation to situation so that in one situation subjects on the average received information leading to the correct decision while in another decision situation the average Diagnosticity led subjects to the wrong decision (see Table 6). These discrepancies in Diagnosticity might have been a factor influencing the number of Pieces of Information a subject sought.

Pieces of Information themselves did not correlate with Accuracy, the across situation correlation coefficient being $-.03(p>.05, \underline{d f}=72)$ (see Table 4). In light of the numerous intervening variables that could have affected Decision Accuracy, it was decided, post hoc, to reformulate and redefine, at least for one of the four decision situations, the variable Decision Accuracy to reflect whether or not the decision made 
by the subject was an appropriate decision given the kind of information the subject had obtained.

Decision situation S (see Appendix A) was chosen for this purpose because, among the four situations, it had the greatest correlation between Diagnosticity and Accuracy $(\underline{r}=+.72, \underline{p}<.001$, df $=72)$, and the only statistically significant correlations between $\mathrm{D}$-score and the decision-making variables Pieces of Information and Confidence (see Table 2).

The new Appropriateness variable is operationally defined in terms of whether the subject's judgment was based on a likelihood ratio greater than 1. The Unbiased Likelihood Rule was used to determine whether or not a subject had made an appropriate decision in this situation.

A Pearson product moment correlation between Appropriateness and D-score (situation S) resulted in an $\underline{r}=+.40(\mathrm{p}<.01$, $\underline{\text { df }}=72)$. This suggests that more dogmatic persons are more likely to make appropriate decisions. Unfortunately, because this study did.not include an intelligence measure it is not possible to determine the extent to which intelligence may have contributed to this finding. It is suggested that a future study include both an intelligence measure and an Appropriateness variable.

Two additional comments, one having to do with differences among the four situations used to measure decision-making behaviors and the other having to do with differences among the three measures of openand closedmindedness, are warranted.

1. The across-situations correlation coefficient between Diagnosticity and Accuracy of $+.70(\mathrm{p}<.001$, $\underline{\mathrm{df}}=72)$ suggests that subjects did to a large extent perform the four tasks properly. For situation $F$ 
this correlation was only $+.34(\mathrm{p}<.05, \underline{\mathrm{df}}=72)$. A test for the difference between dependent correlations showed that this correlation coefficient was significantly different from the overall correlation coefficient of +.70 between Diagnosticity and Accuracy $(\underline{t}=2.66, \mathrm{P}<.001$, $\underline{\mathrm{df}}=72)$. Correlations for the remaining three situations ranged from +.61 to +.72 , with situation $S$ showing the closest relationship between Diagnosticity and Accuracy (see Table 5). From this finding it may be inferred that performance on the first task was impaired because it was relatively unfamiliar.

While the data indicated that subjects were consistent both in the number of Pieces of.Information they sought and in the Confidence ratings they gave from situation to situation, they did not indicate this same consistency for the variables Decision Change and Accuracy (see Table 4).

While the experimental design was set up, not to test a variety of cognitive tasks represented by the four situations, but rather to test an essentially similar cognitive task four times and while there were statistically significant correlations across situations, it is clear from an examination of the situation-by-situation correlations that situation S (see Appendix A) contributed the bulk of the statistically significant findings (see Table 2). It is not clear why situation $S$, more than the other situations contributed to the overall significant relationship between $\mathrm{D}$-score and Pieces of Information. This issue should be addressed in a future study.

2. The Dogmatism agreement, or P-score, as predicted by Korn and Giddan (1964) correlated very highly +.94 with the D-score. The P-score obtained essentially the same results as predictor of the decision making 
behaviors under examination (see Table 2). The variations in correlations affected by the $P$-score were not substantial enough to warrant comparisons of its predictive abilities and that of the D-score.

The Conservatism score (C-score) failed to serve as predictor of any of the decision-making behaviors (see Table 2). The theoretical construct of Conservatism, according to Nias (1973) sees the person who scores high on the Conservatism scale as someone who would tend to avoid making decisions, as someone who has "a tendency to dislike and avoid situations that involve a great deal of response uncertainty-need conflict, decision-making etc." (p. 261). It would seem plausible that for such a person to be forced to make a decision would cause considerable conflict, hence cognitive defense mechanisms could be expected to influence the decision-making behavior.

The consistent pattern of very low, non-significant correlations across all decision-making variables in each of the situations suggests perhaps that the Conservatism scale is more of an attitude measure than a personality'measure. According to Janis and Mann (1977) "the psychological laws of opinion and attitude change are not necessarily the same as the psychological laws of decision making . . " (p. 5).

The predictor variables Sex and Age correlated with none of the decision-making behaviors nor with the other predictor variables (see Table 2).

An expected result that was not confirmed by the data in this study was a sex difference for D-scores. White and Alter (1965) found that women had consistently scored lower throughout the studies they examined for a summary report of normative information on the $D$-scale. A $t$-test 
for differences between the independent means showed no statistically significant difference $\underline{t}=.48(\mathrm{p}>.05, \underline{\mathrm{df}}=.87)$ between the D-scores obtained in this study by women and men. It is possible that the cultural changes that have taken place regarding women within the past 14 years served to eradicate. the differences White and Alter found in 1965. White and Alter caution in their article "that the scale is highly sensitive to subcultural differences" (p. 969).

\section{Summary}

Persons with high D-scores tended to arrive at decisions on the basis of less information than persons with low $D$-scores $(\underline{r}=-.22$, $\mathrm{p}<.05)$ and to make more appropriate use of information $(\underline{r}=+.40$, $\mathrm{P}<.01$ ), yet they showed no tendency to differ in either accuracy $(\underline{r}=+.06, \underline{p}>.05)$ or confidence $(\underline{r}=-.18, \underline{p}>.05)$. Furthermore, they showed no tendency to be less able to reverse an earlier decision $(\underline{r}=+.04, \underline{p}>.05)$.

Whaterpating of this pattern of results, not mutually exclusive, suggest themselves. First, it is quite possible that the effective variable distinguishing high and low D-score persons in this study was intelligence, rather than dogmatism. There is evidence (Taylor \& Dunnette, 1974) that the D-score reflects both intelligence and dogmatism. There is also evidence (Janis \& Mann, 1977) to suggest that awareness of the possibility of serious losses is a necessary condition for the expression of defensive avoidance; and it is not difficult to imagine that the decision situations employed in the present study failed to provide this necessary condition for activating dogmatic behaviors predictable from the D-score, thus leaving the D-score with only intelligence to predict. 
The picture of a person who makes efficient use of information in arriving at decisions is certainly close to that of a person high in general intelligence. One prediction from this interpretation is that partialling out inteiligence would reduce the correlations between $D$-score and both Pieces of Information and Appropriateness to zero.

A second interpretation is also possible, that the effective variable distinguishing high and low D-score persons in this study was dogmatism, after all, and that more dogmatic persons are, in some situations, at least, indeed more effective decision makers than less dogmatic persons. There is evidence that more dogmatic, or authoritarian, persons tend to be more anxious and concerned about possible negative consequences (Adorno et a1., 1950) than less dogmatic, or authoritarian, persons; and there is evidence (Janis \& Mann, 1977) to suggest that enhanced awareness of possible negative consequences improves decision quality. These two facts, taken by themselves, would lead one to expect more dogmatic persons to make better decisions, reversing the negative picture of dogmatic persons painted by Rokeach (1960) and Long and Ziller (1965). An additional fact, however, suggests that, even if this much is granted, a qualification may be in order. The well-supported (see Anderson, 1975, p. 155) Yerkes-Dodson law states that problem-solving performance is at its best at an intermediate, rather than at an extremely high or extremely low, level of motivation or conflict. It is quite possible that more dogmatic persons bring enough motivation, conflict, or anxiety to the situation to put themselves nearer the optimum in low-conflict situations, where they would outperform less dogmatic persons, yet push them beyond the optimum in high-conflict situations, where they would 
then perform less well than less dogmatic persons. One prediction from this interpretation is that increasing the level of situation-induced motivation, conflict, or anxiety would initially reduce the correlations between D-score and both Pieces of Information and Appropriateness to zero and eventually reverse their direction. 
Table 1

Comparison Figures (Correlations) Between Results of This Study

And Those of Other Authors' Correlations Between

Dogmatism and Pieces of Information etc.

Variables

Authors

$\begin{array}{cccc}\text { Long \& Ziller } & \text { Taylor } & \text { Taylor \& } & \text { Jolin } \\ (1965) & \text { (1972) } & \text { Dunnette } & \text { (1979) }\end{array}$

Dogmatism Dogmatism Dogmatism

Total Sit. S

Pieces of

Information

$-.20 *$ to

$-.17 \quad-.16$

$-.22 *-.29 *$

$-.32 * *$

Decision

Change

$\mathrm{X}$

$-.10 \quad-.09$

$+.04$

$-.11$

Accuracy

X

$+.23 *$

$+.23 *$

$+.06$

$+.07$

Confidence

$\mathrm{x}$

$+.27 *$

$+.27 *$

$-.18$

$-.29 * *$

$$
\begin{aligned}
* & =p<.05 \\
* * & =p<.01
\end{aligned}
$$




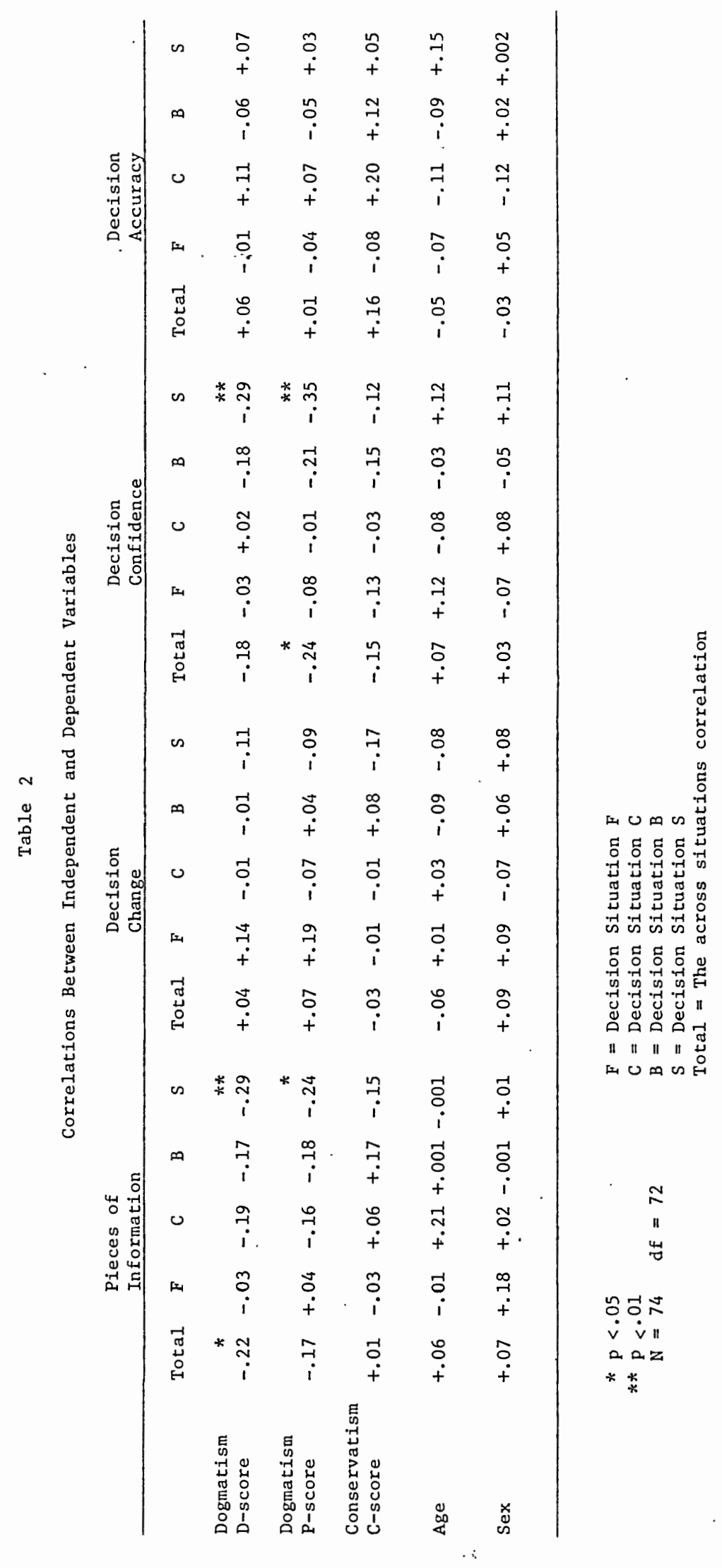


Table 3

Results of a Test for Significance Between

Criterion Correlations

\begin{tabular}{lcccc}
\hline & \multicolumn{1}{c}{$\begin{array}{l}\text { Dogmatism/ } \\
\text { Pieces of Inform. }\end{array}$} & $\begin{array}{l}\text { Dogmatism/ } \\
\text { Opinion Change }\end{array}$ & $\begin{array}{l}\text { Dogmatism/ } \\
\text { Confidence }\end{array}$ & $\begin{array}{l}\text { Dogmatism/ } \\
\text { Accuracy }\end{array}$ \\
\hline F and C & 1.06 & .83 & .06 & .63 \\
$\mathrm{~F}$ and B & .91 & .83 & .99 & .31 \\
$\mathrm{~F}$ and S & 1.88 & .19 & 1.88 & .37 \\
$\mathrm{C}$ and B & .12 & .00 & 1.06 & .31 \\
$\mathrm{C}$ and S & .67 & .63 & $1.97 *$ & .24 \\
$\mathrm{~B}$ and S & .81 & .63 & .74 & .06 \\
\hline
\end{tabular}

the values in this table are $t$ values

$N=74 \quad d f=72$

$*=p<.05$ 


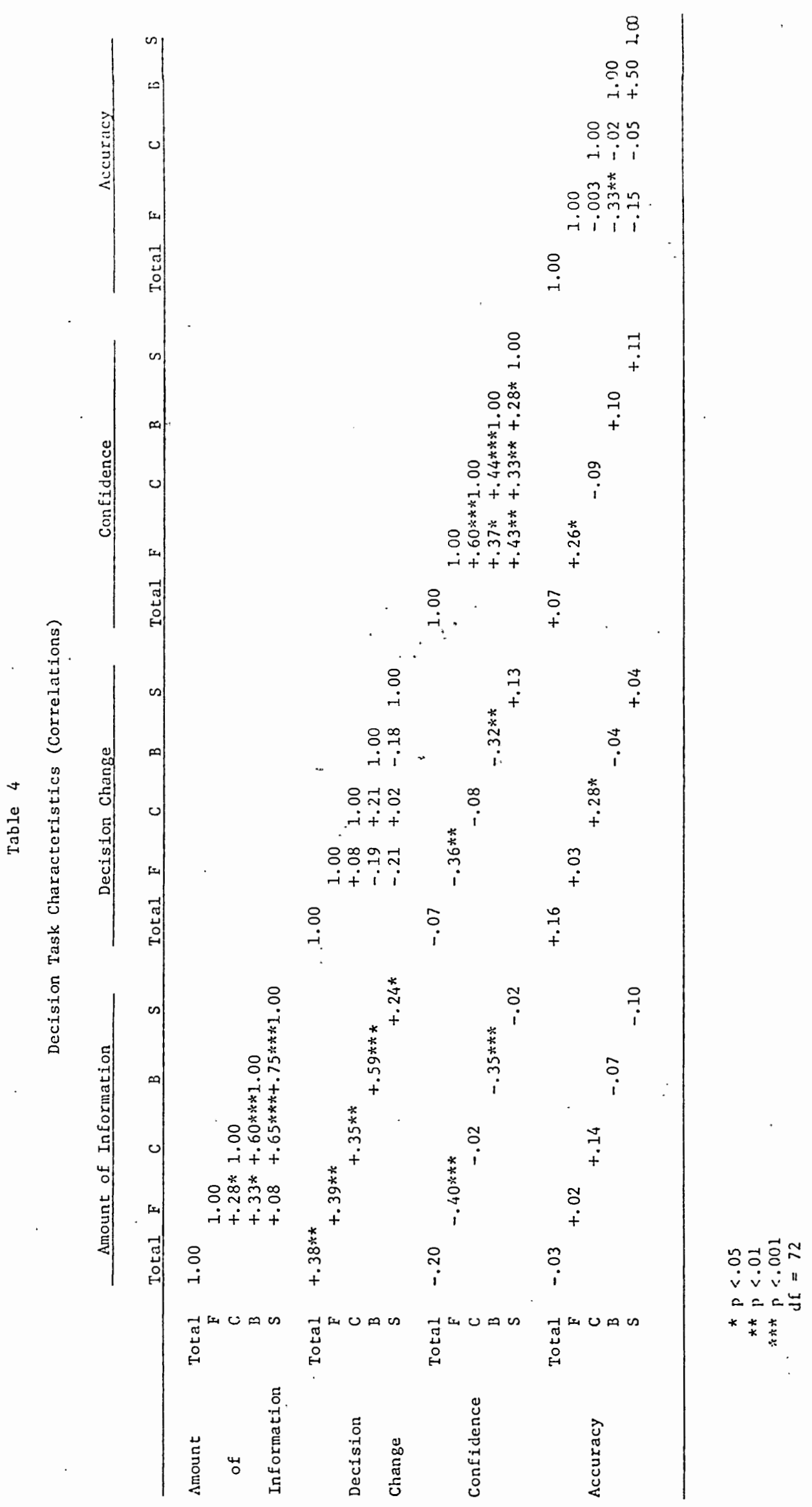




\section{Table 5}

Correlations Between Diagnosticity

and Decision Variables

\section{Diagnosticity}

Total

$\begin{array}{lllll}\text { F } & \text { C } & \text { B } & \text { S }\end{array}$

$\begin{array}{lllllll}\text { Pieces of Information } & \text { Total } & -.16 & & & & \\ & \text { F } & & +.16 & & & \\ \text { C } & & . & -.03 & & \\ \text { B } & & & & -.20 & -.43 * * * * \\ & \text { S } & & & & & -.43 *\end{array}$

Decision Change

$$
\begin{array}{llllll}
\text { Total } & +.04 & & & & \\
\text { F } & & -.10 & & & \\
\text { C } & & & -.05 & & \\
\text { B } & & & & -.20 & \\
\text { S } & & & & & -.09
\end{array}
$$

\begin{tabular}{|c|c|}
\hline$*=p<.05$ & Total $=$ Across situations correlation \\
\hline$* *=p<.01$ & $\mathrm{~F} \quad=$ situation $\mathrm{F}$ \\
\hline$* * *=\mathrm{p}<.001$ & $=$ situation $\mathrm{C}$ \\
\hline & $=$ sïtuation $B$ \\
\hline $\begin{array}{l}N=74 \\
d f=72\end{array}$ & $=$ situation $\mathrm{S}$ \\
\hline
\end{tabular}

Confidence

$$
\begin{array}{llllll}
\text { Total } & +.16 & & & & \\
\text { F } & & -.02 & & & \\
\text { C } & & & +.13 & & \\
\text { B } & & & & +.06 & \\
\text { S } & & & & & +.09
\end{array}
$$

Accuracy

$$
\begin{array}{lc}
\text { Total } & +.70 * * * \\
\text { F } & +.34 * * \\
\text { C } & +.61 * * * \\
\text { B } & +.71 * * * \\
\text { S } & +.72 * * *
\end{array}
$$


Table 6

Distributional Statistics for Predictor

and Criterion Variables

\begin{tabular}{|c|c|c|c|c|c|c|c|}
\hline & Variable & Mean & SD & Mode & Median & Range & Absolute Range \\
\hline & Age & 25.26 & 6.34 & 23 & 23.32 & $15-49$ & $\mathrm{n} / \mathrm{a}$ \\
\hline & D-score & 137.10 & 22.73 & 116 & 137.50 & $81-213$ & $40-280$ \\
\hline & P-score & 15.78 & 5.27 & 17 & 15.93 & $4-36$ & $0-40$ \\
\hline & C-score & 36.35 & 10.63 & 24 & 36.50 & $14-61$ & $0-100$ \\
\hline & Total & 23.53 & 7.09 & 13 & 23 & $13-40$ & $12-40$ \\
\hline $\begin{array}{l}\text { Pieces } \\
\text { of } \\
\text { Information }\end{array}$ & $\begin{array}{l}\text { F } \\
C \\
B \\
S\end{array}$ & $\begin{array}{l}6.73 \\
5.23 \\
5.37 \\
6.20\end{array}$ & $\begin{array}{l}2.66 \\
1.91 \\
2.22 \\
2.59\end{array}$ & $\begin{array}{r}10 \\
3 \\
3 \\
3\end{array}$ & $\begin{array}{l}6.83 \\
5.07 \\
4.93 \\
6.10\end{array}$ & $\begin{array}{l}3-10 \\
3-10 \\
3-10 \\
3-10\end{array}$ & $\begin{array}{l}3-10 \\
3-10 \\
3-10 \\
3-10\end{array}$ \\
\hline & Total & 1.47 & 1.48 & 0.0 & 1.25 & $0-6$ & $0-32$ \\
\hline $\begin{array}{l}\text { Decision } \\
\text { Change }\end{array}$ & $\begin{array}{l}F \\
C \\
B \\
S\end{array}$ & $\begin{array}{l}.50 \\
.30 \\
.47 \\
.20\end{array}$ & $\begin{array}{r}.94 \\
.57 \\
1.01 \\
.55\end{array}$ & $\begin{array}{l}0.0 \\
0.0 \\
0.0 \\
0.0\end{array}$ & $\begin{array}{l}.21 \\
.15 \\
.15 \\
.08\end{array}$ & $\begin{array}{l}0-4 \\
0-2 \\
0-4 \\
0-2\end{array}$ & $\begin{array}{l}0-8 \\
0-8 \\
0-8 \\
0-8\end{array}$ \\
\hline & Total & 3.49 & .41 & 3.50 & 3.52 & $2-4$ & $2-4$ \\
\hline Confidence & $\begin{array}{l}\text { F } \\
\text { C } \\
B \\
S\end{array}$ & $\begin{array}{l}.84 \\
.87 \\
.87 \\
.89\end{array}$ & $\begin{array}{l}.16 \\
.10 \\
.10 \\
.19\end{array}$ & $\begin{array}{l}.90 \\
.90 \\
.80 \\
.90\end{array}$ & $\begin{array}{l}.89 \\
.90 \\
.87 \\
.92\end{array}$ & $\begin{array}{l}.5-1.0 \\
.6-1.0 \\
.7-1.0 \\
.5-1.0\end{array}$ & $\begin{array}{l}.5-1.0 \\
.5-1.0 \\
.5-1.0 \\
.5-1.0\end{array}$ \\
\hline & Total & 6.57 & 1.04 & 6.00 & 6.60 & $4-8$ & $\begin{array}{l}4=\text { none correct } \\
8=\text { all correct }\end{array}$ \\
\hline Accuracy & $\begin{array}{l}\mathrm{F} \\
\mathrm{C} \\
\mathrm{B} \\
\mathrm{S}\end{array}$ & $\begin{array}{l}1.73{ }^{\circ} \\
1.57 \\
1.83 \\
1.43\end{array}$ & $\begin{array}{l}.45 \\
.50 \\
.38 \\
.50\end{array}$ & $\begin{array}{l}2.00 \\
2.00 \\
2.00 \\
1.00\end{array}$ & $\begin{array}{l}1.82 \\
1.62 \\
1.90 \\
1.38\end{array}$ & $\begin{array}{l}1-2 \\
1-2 \\
1-2 \\
1-2\end{array}$ & $\begin{array}{l}1=\text { one correct } \\
2=\text { two correct }\end{array}$ \\
\hline & Total & 43.77 & 5.10 & 41.00 & 43.50 & $36-56$ & $0-80$ \\
\hline Diagnosticity & $\begin{array}{l}F \\
C \\
B \\
S\end{array}$ & $\begin{array}{r}12.5 \\
10.67 \\
11.83 \\
8.77\end{array}$ & $\begin{array}{l}2.19 \\
2.23 \\
2.37 \\
3.26\end{array}$ & $\begin{array}{r}13.00 \\
10.00 \\
11.00 \\
7.00\end{array}$ & $\begin{array}{r}12.75 \\
10.50 \\
12.00 \\
8.83\end{array}$ & $\begin{array}{l}8-18 \\
7-16 \\
6-15 \\
2-15\end{array}$ & $\begin{array}{l}0-20 \\
0-20 \\
0-20 \\
0-20\end{array}$ \\
\hline
\end{tabular}




\section{Table 7}

Correlations Between Predictor Variables

\begin{tabular}{|c|c|c|c|c|c|}
\hline & Dogmatism & & Conservatism & Age & $\underline{\text { Sex }}$ \\
\hline & D-score & P-score & $\mathrm{C}$-score & & \\
\hline D-score & 1.00 & & · & & \\
\hline P-score & $+.94 * * *$ & 1.00 & & & \\
\hline C-score & $+.22 *$ & +.13 & 1.00 & & \\
\hline Age & -.12 & -.14 & -.04 & 1.00 & \\
\hline Sex & +.08 & +.12 & +.15 & -.05 & 1.00 \\
\hline
\end{tabular}

$\begin{array}{rlr}*=p<.05 & N=74 \\ * *=p<.01 & \mathrm{df}=72 \\ * * *=p<.001 & \end{array}$




\section{REFERENCES}

Adorno, T. W., Frenkel-Brunswick, E., Levinson, D. J., \& Sanford, R. N. The authoritarian personality. New York: Harper, 1950.

Allport, G. W., \& Postman, L. The psychology of rumor. New York:

Henry Holt and Company, 1947.

Anderson, B. F. Cognitive psychology. New York: Academic Press, 1975. Couch, H., \& Keniston, K. Yeasayers and naysayers: Agreeing response set as a personality variable. Journal of Abnormal and Social Psychology, 1960, 60, 151-174.

Edwards, W. Conservatism in human judgement, in Formal representation of human judgement. Kleinmuntz, B. (Ed.) New York: John Wiley \& Sons, Inc., 1969.

Ehrlich, H. J. Dogmatism and learning. Journal of Abnormal and Social Psychology, 1961, 62, 148-149. (a)

Ehrlich, H. J., \& Lee, D. Dogmatism, learning and resistance to change: A review and new paradigm. Psychological Bulletin, 1969, 71, 149-260.

Feger, H. Konflikterleben und konfliktverhalten. Bern Stuttart Wien: Verlag Hans Huber, 1978.

Frenkel-Brunswick, E. Intolerance of ambiguity as an emotional perceptual personality variable. Journal of Personality, $1949, \underline{18}$, 108-143.

Janis, I. L., \& Mann, L. Decision making. New York: The Free Press, 1977. Kendall, M. G., \& Smith, B. B. Randomness and random sampling numbers. Journal of the Royal Statistical Society, 1938, 101, 147-166.

Korn, H. A., \& Giddan, N. S. Scoring methods and construct validity of the Dogmatism scale. Educational and Psychological Measurement, 
$1964, \underline{24}, 867-874$.

Lichtenstein, E., Quinn, R., \& Hover, G. Dogmatism and acquiescent response set. Journal of Abnormal and Social Psychology, 1961, 63, 636-638.

Long, B. H., \& Ziller, R. C. Dogmatism and predecisional information search. Journal of Applied Psychology, 1965, 49, 376-378.

Maslow, A. H. Motivation and personality. New York: Harper and Bros., 1954.

Nias, K. B. Attitudes to the common market: A case study in conservatism, in The psychology of conservatism, Wilson, G. D. (Ed.) Academic Press: London, 1973.

Nias, R. B., Wilson, G. D., \& Woodbridge, J. M. Test-re-test results on the Conservatism scale completed under conditions of anonymity and identification. British Journal of Social and Clinical Psychology, 1971, 10, 282-283. In The psychology of conservatism. Wilson, G. D. (Ed.) London: Academic Press, 1973.

Peabody, D. Attitude content and agreement set in scales of authoritarianism, and economic conservatism. Journal of Abnormal and Social Psychology, 1961, $63,1-11$.

, Authoritarianism scales and response bias. Psychological Bulletin, $1966, \underline{65}, 11-23$.

Plant, W. T. Rokeach's dogmatism scale as a measure of general authoritarianism. Psychological Reports, 1960, $\underline{6}, 164$.

Pruitt, D. G. Informational requirements in decision making. American Journal of Psychology, 1961, 74, 433-439. 
Pyron, B., \& Lambert, P. The generality of simplicity-complexity of social perception in a high-school population. Journal of Psychology, $1967, \underline{66}, 265-273$.

Rokeach, M. The nature and meaning of dogmatism. Psychological Review, $1954,61,194-204$.

- The open and closed mind. New York: Basic Books, 1960.

Schneider, J., \& Minkmar, H. Deutsche neukonstruktion einer konservatismusskala. Diagnostica, 1972. In The psychology of conservatism. Wilson, G. D. (Ed.) London: Academic Press, 1973.

Stanley, G., \& Martin, J. How sincere is the dogmatic? Psychological Review, 1964, 71, 331-334.

Taylor, R. N. Risk taking, dogmatism, and demographic characteristics of managers as correlates of information processing and decision making behaviors. Proceedings, 80th Annual Convention, APA, $1972,443-444$.

Taylor, R. N., \& Dunnette, M. D. Influence of dogmatism, risk-taking, and intelligence on decision-making strategies for a sample of industrial managers. Journal of Applied Psychology, 1974, 59, 420-423.

Vacchiano, R. B., Schiffman, D. C., \& Strauss, P. S. Factor structure of the dogmatism scale. Psychological Reports, 1967, 20, 847-852. Vacchiano, R. B., Strauss, P. S., \& Hochman, L. The open and closed mind: A review of dogmatism. Psychological Bulletin, 1969, 71, 261-273.

White, B. J., \& Alter, R. D. Some norms for the DS. Psychological Reports, $1966,19,967-969$. 
White, B. J., Alter, R. D., Rardom, M. Authoritarianism, dogmatism and usage of conceptual categories. Journal of Personality and Social Psychology, 1965, 2, 293-295.

Wilson, G. D. The concept of Conservatism, in The psychology of conservatism. Wilson, G. D. (Ed.) London: Academic Press, 1973.

Wilson, G. D., \& Patterson, J. R. A new measure of conservatism. British Journal of Social and Clinical Psychology, 1968, $\underline{7}, 264-269$. Zagona, S. V., \& Zurchner, L. A. Notes on the reliability and validity of the dogmatism scale. Psychological Reports, 1965, 16, 12341236. 
APPENDIX A 
PLEASE PROVIDE THE FOLLOWING INFORMATION:

Age Sex Major in College

Freshman Sophomore Junior Senior Other

INSTRUCTIONS :

Each of you will receive four different decision situations, it is your task to come to a decision in each of the four situations.

First you will be asked to indicate which of the two alternatives you would choose.

Secondly, you will be asked whether the choice you made represents a PRELIMINARY Or a FINAZ DECISION

-if your choice represents a PRELIMINARY DECISION you may go on to obtain the next piece of information pertinent to your decision situation.

-if your choice represents a FINAL DECISION, you may regard this particular decision task as completed. All that will remain for you to do before you may proceed to the next task will be to indicate on the scale how certain you are that the decision you have just made is correct.

Please read all the information carefully and mark your answers clearly. Please do not skip parts of the task for it makes evaluation of your effort difficult.

Thank you for your participation. 


\section{DECISION SITUATION F}

You have been a casual gambler for several years, and you have acquired the reputation of being unbeatable at your particular game. Your success is due to your highly developed skill of assessing odds and knowing when to quit. One day you are challenged publicly by a person who says he can beat you at your own game--at assessing odds and knowing when to quit.

You accept the challenge, which you agree to carry out in front of your gambling companions. You and your opponent have agreed to bet $\$ 1,000.00$ on the following game:

You have two bookbags each with 100 poker chips.

BAG I has 70 RED chips and 30 BLUE chips.

BAG II has 30 RED chips and 70 BLUE chips.

Below are shown some chips which were drawn from one of the two bags.

YOU ARE TO DECIDE WHETHER THEY WERE DRAWN FROM BAG I OR BAG II.

You will be given an opportunity to get additional pieces of information, the winner will be the one who has the correct answer with the fewest pieces of information.

At this point please answer:

1. Are the three chips at the left most likely to have come from (circle your choice) BAG I BAG II

-please indicate on the scale how certain you are that this decision is correct:

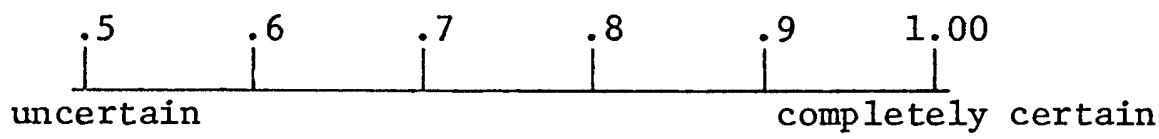

2. If this is only a PRELIMINARY DECISION and you want more information, check the box on the left, skip step 3, remove the next dot, and go on to step 4.

3. If this is your FINAL DECISION, please check box: You have now completed decision SITUATION F. Turn this set of pages face down and go on to the next decision situation. 
4. Are the four chips so far most likely to have come from (circle your choice) BAG I BAG II

-indicate certainty on scale:

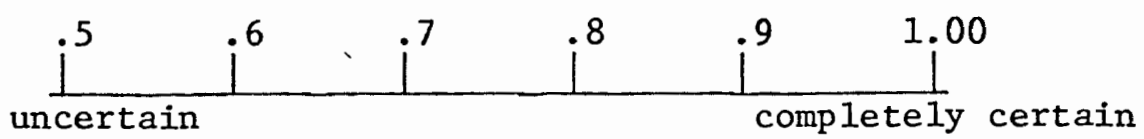

5. PRELIMINARY DECISION: check box; skip step 6, remove next dot and go on to step 7 .

6. FINAL DECISION: check box: and move on to next DECISION SITUATION.

7. Are the five chips so far most likely to have come from (circle your choice) BAG I BAG II

-indicate certainty on scale:

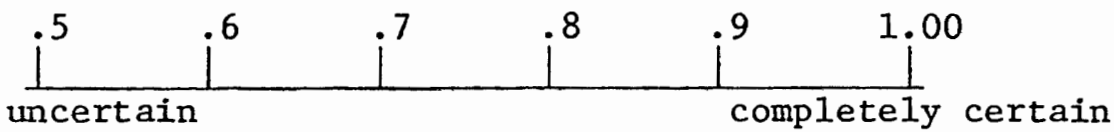

8. PRELIMINARY DECISION: check box, skip step 9, remove next dot and go on to step 10.

9. FINAL DECISION: check box: and move on to next DECISION SITUATION

10. Are the six chips so far most likely to have come from (circle your choice) BAG I BAG II

-indicate certainty on scale:

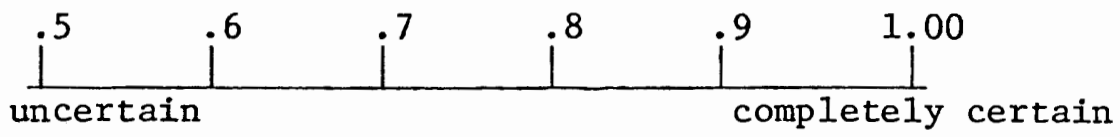

11. PRELIMINARY DECISION: check box, skip step 12, remove next dot and go on to step 13.

12. FINAL DECISION: check box: and move on to next DECISION SITUATION.

13. Are the seven chips so far most likely to have come from (circle your choice) BAG I BAG II

-indicate certainty on scale:

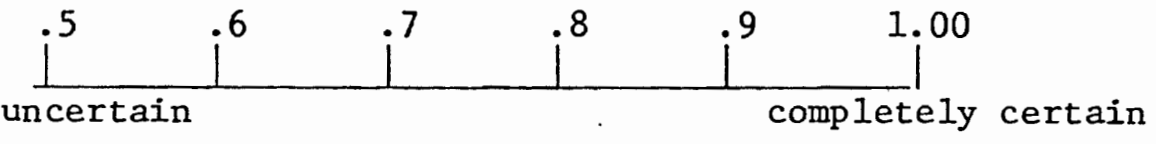


14. PRELIMINARY DECISION; check box, skip step 15, remove next dot and go on to step 16.

15. FINAL DECISION: check box: and move on to next DECISION SITUATION.

16. Are the eight chips so far most likely to have come from (circle your choice) BAG I BAG II

-indicate certainty on scale:

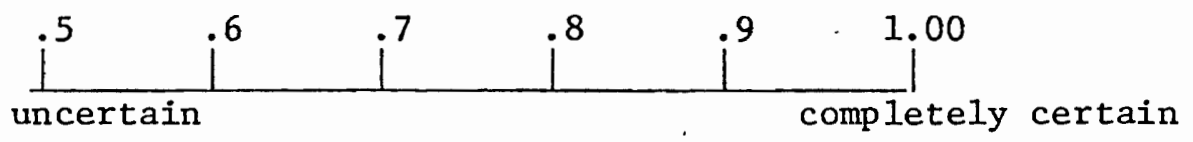

17. PRELIMINARY DECISION: check box, skip step 18, remove next dot and go on to step 19.

18. FINAL DECISION: check box: and move on to next DECISION SITUATION.

19. Are the nine chips so far most likely to have come from (circle your choice) BAG I BAG II -indicate certainty on scale:

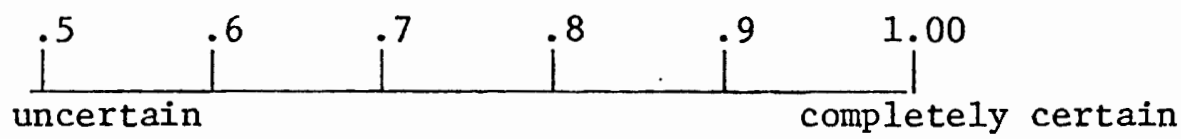

20. PRELIMINARY DECISION: check box, skip step 21, remove next dot and go on to step 22 .

21. FINAL DECISION: check box: and move on to next DECISION SITUATION.

22. Are the ten chips so far most likely to have come from (circle your choice) BAG I BAG II

-indicate certainty on scale:

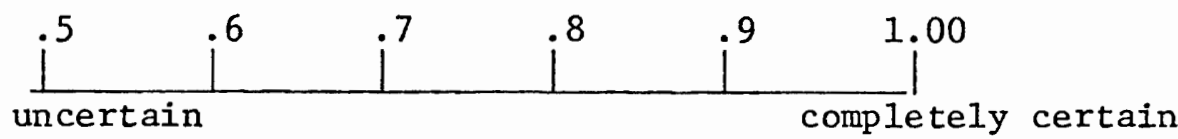

23. PRELIMINARY DECISION: check box:

24. FINAL DECISION: check box: and move on to next DECISION SITUATION. 


\section{DECISION SITUATION C}

The company you work for offers a six-months decision-making training course to selected employees. Completion of this training would assure you of a much more satisfying position than the one you currently hold and would mean a salary increase of $\$ 5000.00$ per year.

The following simple screening device is used as the basis for selection.

You will be admitted if, in the decision situation below, you have come to a correct decision using the least number of additional pieces of information.

In this situation you have two basketbali teams.

TEAM I makes baskets from the free-throw line $80 \%$ of the time. TEAM II makes baskets from the free-throw line $50 \%$ of the time. Below is a series of random attempts from the free-throw line. YOU ARE TO DECIDE WHETHER THESE SHOTS WERE MOST LIKELY TO HAVE BEEN MADE BY TEAM I OR TEAM II.

(t) indicates a successful shot

(-) indicates an unsuccessful shot

At this point please answer:

1. Are the three shots at the left most likely to have come from (circle your choice) TEAM I

TEAM II

-please indicate on the scale how certain you are that this decision is correct

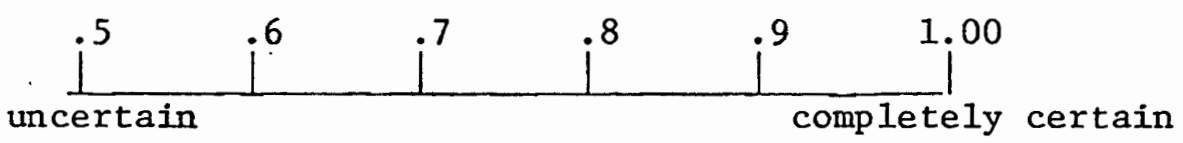

2. If this is only a PRELIMINARY DECISION and you want more information, check the box on the left, skip step 3 , remove the next dot, and go on to step 4 .

3. If this is your FINAI DECISION, PLEASE check box: You have now completed DECISION SITUATION $\mathrm{C}$. Turn this set of pages face down and go on to the next decision situation. 
4. Are the four shots so far most likely to have come from (circle your choice)

TEAM I

TEAM II

-indicate certainty on scale:

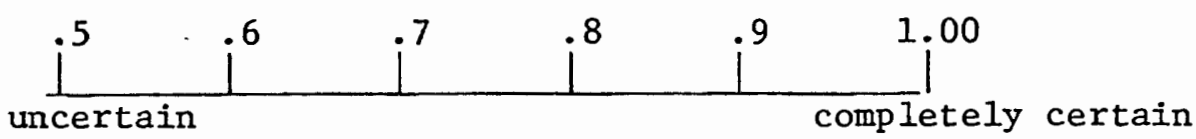

5. PRELIMINARY DECISION: check box, skip step 6, remove next dot and go on to step 7 .

6. FINAL DECISION: check box: and move on to next DECISION SITUATION.

7. Are the five shots so far most likely to have come from (circle your choice) TEAM I

TEAM II

-indicate certainty on scale:

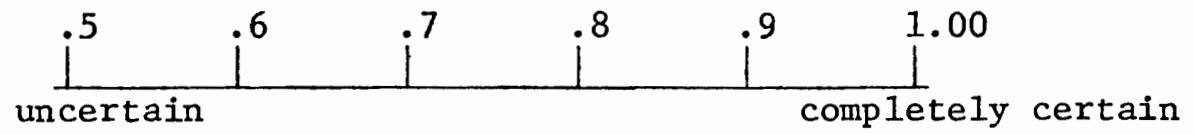

8. PRELIMINARY DECISION: check box, skip step 9, remove next dot and go on to step 10.

9. FINAL DECISION: check box: and move on to next DECISION SITUATION.

10. Are the six shots so far most likely to have come from (circle your choice)

-indicate certainty on scale:

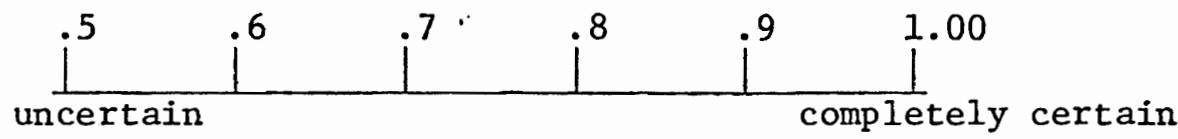

11. PRELIMINARY DECISION: check box, skip step 12, remove next dot and go on to step 13.

12. FINAL DECISION: check box: and move on to next DECISION SITUATION. 
13. Are the seven shots so far most likely to have come from (circle your choice)

TEAM I

TEAM II

-indicate certainty on scale:

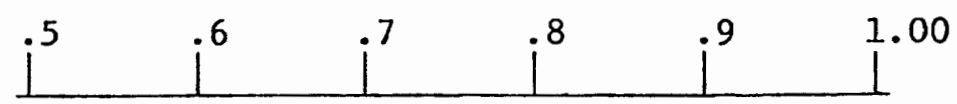

uncertain

completely certain

14. PRELIMINARY DECISION: check box, skip step 15, remove next dot and go on to step 16.

15. FINAL DECISION: check box: and move on to next DECISION SITUATION.

16. Are the eight shots so far most likely to have come from (circle your choice)

TEAM I

TEAM II

-indicate certainty on scale:

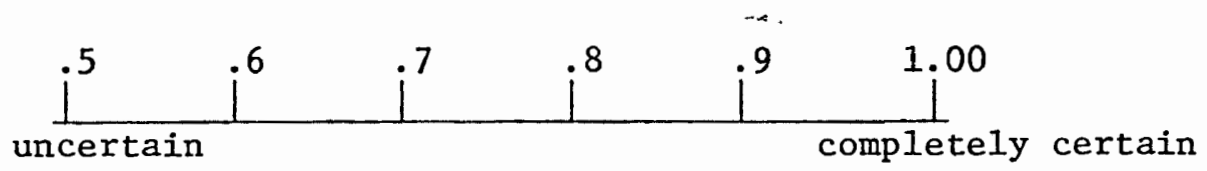

17. PRELIMINARY DECISION: check box, skip step 18, remove next dot and go on to step 19.

18. FINAL DECISION: check box: and move on to next DECISION SITUATION.

19. Are the nine shots so far most likely to have come from (circle your choice)

TEAM I

TEAM II

-indicate certainty on scale:

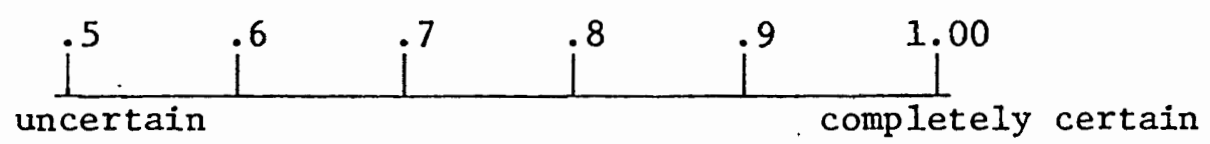

20. PRELIMINARY DECISION: check box, skip step 21, remove next dot and go on to step 22 .

21. FINAL DECISION: check box: and move on to next DECISION SITUATION. 
22. Are the ten shots so far most likely to have come from (circle your choice)

-indicate certainty on scale:

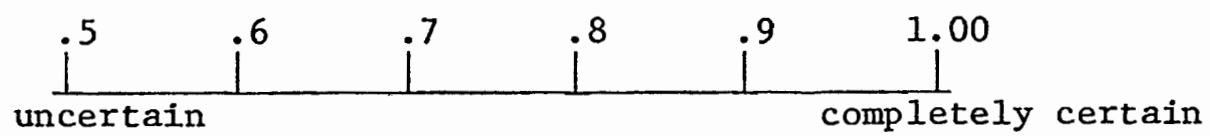

23. PRELIMINARY DECISION: check box:

24. FINAL DECISION: check box: and move on to next DECISION SITUATION. 


\section{DECISION SITUATION B}

You are being tried out for a new position on a commercial fishing vessel. Your job is to determine whether schools of fish you encounter are or are not profitable to fish. In order to make the correct decision, you cast a line and examine your catch for size. It is important both for you to make correct decisions and to make them on the basis of as few casts as possible. You are aware that, in order to get this interesting and well-paid position, you will be able to make only an occasional mistake.

Your radar has just picked up a school of fish in the vicinity of your boat. The fish in this area come in two types, which differ only in size. $60 \%$ of the fish of Type I are above the legal minimum size, while only $30 \%$ of those of Type II are above the minimum. Type I is profitable to fish, while Type II is not.

Below are the results from the first few casts.

(+) indicates a fish above legal minimum size

$(-)$ indicates a fish below legal minimum size

At this point answer:

1. Are the three fish at the left most likely to have come from (circle your choice)

PROFITABLE SCHOOL

NON-PROFITABLE SCHOOL

Please indicate on the scale how certain you are that this decision is correct:

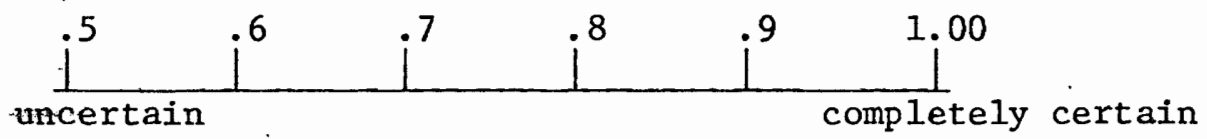

2. If this is only a PRELIMINARY DECISION and you want more information, check the box on the left, skip step 3, remove the next dot, and go on to step 4.

3. If this is your FINAL DECISION, please check this box:

You have now completed DECISION SITUATION B. Turn this set of pages face down and go on to the next decision situation.

4. Are the four fish so far most likely to have come from (circle your choice)

PROFITABLE SCHOOL NON-PROFITABLE SCHOOL

-indicate certainty on scale.

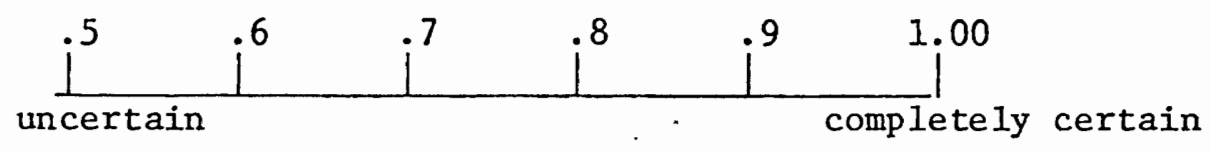


5. PRELIMINARY DECISION: check box, skip step 6, remove next dot and move on to step 7 .

6. FINAL DECISION: check box: and move on to next DECISION SITUATION.

7. Are the five fish so far most likely to have come from the (circle your choice)

PROFITABLE SCHOOL NON-PROFITABLE SCHOOL

-indicate certainty on scale:

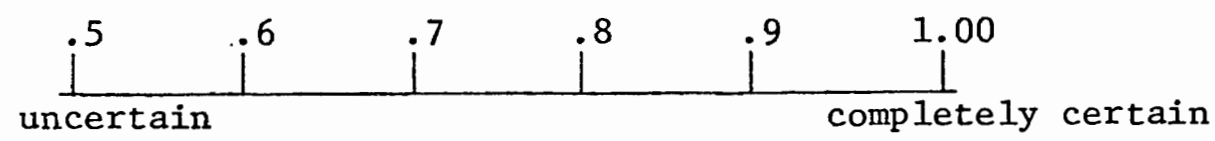

8. PRELIMINARY DECISION: check box, skip step 9, remove next dot and go on to step 10.

9. FINAL DECISION: CHECK BOX: and move on to next DECISION SITUATION.

10. Are the six fish so far most likely to have come from the (circle your choice) PROFITABLE SCHOOL NON-PROFITABLE SCHOOL

-indicate certainty on scale:

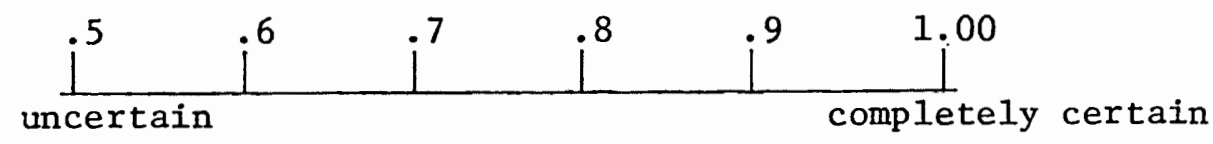

11. PRELIMINARY DECISION: check box, skip step 12, remove next dot and go on to step 13.

12. FINAL DECISION: check box: and move on to next DECISION SITUATION.

13. Are the seven fish so far most likely to have come from the (circle your choice)

PROFITABLE SCHOOL NON-PROFITABLE SCHOOL

-indicate certainty on scale:

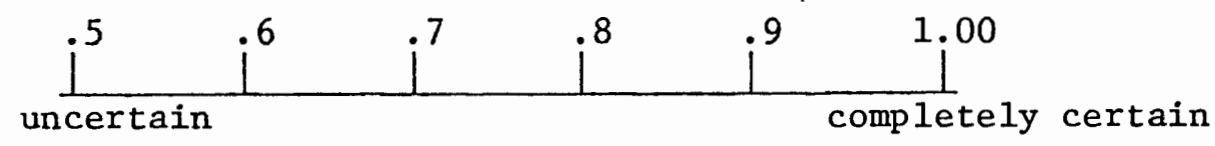

14. PRELIMINARY DECISION: check box, skip step 15, remove next dot and go on to step 16. 
15. FINAL DECISION: check box:

and move on to next DECISION SITUATION.

16. Are the eight fish so far most likely to have come from the (circle your choice)

PROFITABLE SCHOOL NON-PROFITABLE SCHOOL

-indicate certainty on scale:

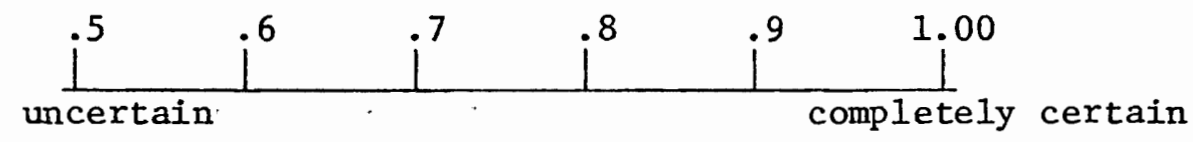

17. PRELIMINARY DECISION: check box, skip step 18, remove next dot and go on to step 19.

18. FINAL DECISION: check box:

and move on to next DECISION SITUATION.

19. Are the nine fish so far most likely to have come

from the (circle your choice)

PROFITABLE SCHOOL

NON-PROFITABLE SCHOOL

-indicate certainty on scale:

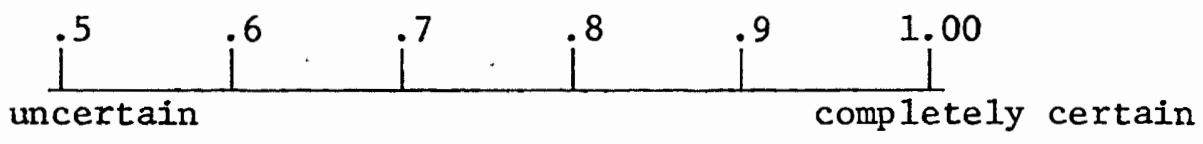

20. PRELIMINARY DECISION: check box, skip step 21, remove next dot and go on to step 22.

21. FINAL DECISION: check box:

and move on to next DECISION SITUATION.

22. Are the ten fish so far most likely to have come

from the (circle your choice)

PROFITABLE SCHOOL

NON-PROFITABLE SCHOOL

-indicate certainty on scale:

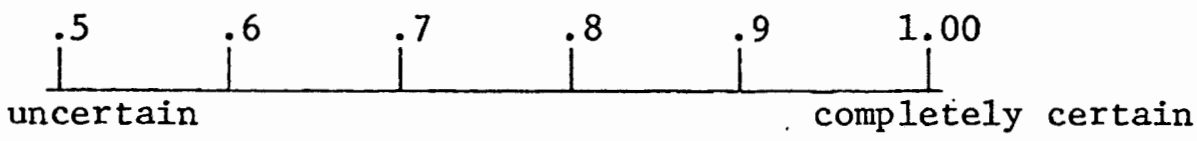

23. PRELIMINARY DECISION: check box:

24. FINAL DECISION: check box:

and move on to next DECISION SITUATION. 


\section{DECISION SITUATION S}

You are a buyer for a large department store. Your assignment is to buy ten thousand pairs of Italian shoes. A regional wholesaler has announced a very good deal on a shipment of Piazzo shoes. From your prior experience you know, however, that there are two Italian firms producing shoes under that name. One of these manufacturers produces a slightly defective shoe, which fails to meet your company's high standards about $20 \%$ of the time. The other manufacturer produces such a slightly defective shoe about $40 \%$ of the time. You ask the wholesaler to let you examine the shipment. Reluctantly, the wholesaler agrees to let you examine a number of randomly selected pairs of shoes. The wholesaler pressures you to hurry up, for other bidders are waiting in line to snap up what to them looks like a great deal.

If you get the shoes that are only about $20 \%$ defective your firm will realize an immediate profit of $\$ 5,000.00$. If you get the shoes that are about $40 \%$ defective, however, your firm will lose $\$ 5,000.00$ and your reputation will be diminished.

Below are the results of a random sampling of shoes.

$(+)$ indicates an acceptable shoe

$(-)$ indicates an unacceptable shoe

At this point please answer:

1. Are the three samples at the left most likely to have come from the (circle your choice) PROFITABLE NON-PROFITABLE SHIPMENT

-please indicate on the scale how certain you are that this decision is correct

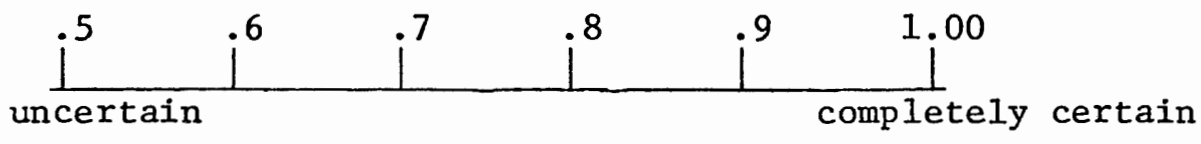

2. If this is only a PRELIMINARY DECISION and you want more information, check the box on the left, skip step 3, remove the dot and go on to step 4.

3. If this is your FINAL DECISION, please check this box: You have now completed DECISION SITUATION S. Turn this set of pages face down and go on to the next decision situation. 
4. Are the four samples so far most likely to have come from (circle your choice)

PROFITABLE NON-PROFITABLE SHIPMENT

-indicate certainty on scale:

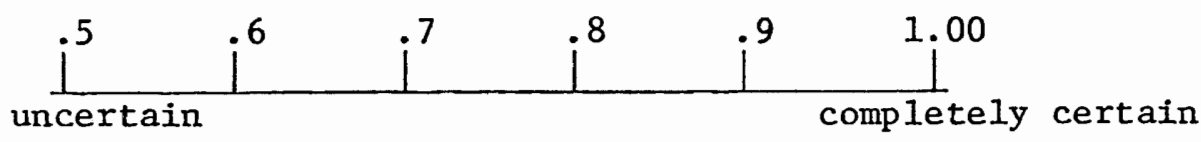

5. PRELIMINARY DECISION: check box, skip step 6, remove next dot and go on to step 7.

6. FINAL DECISION: check box: and move on to next DECISION SITUATION

7. Are the five samples so far most likely to have come from the (circle your choice) PROFITABLE NON-PROFITABLE SHIPMENT

-indicate certainty on scale:

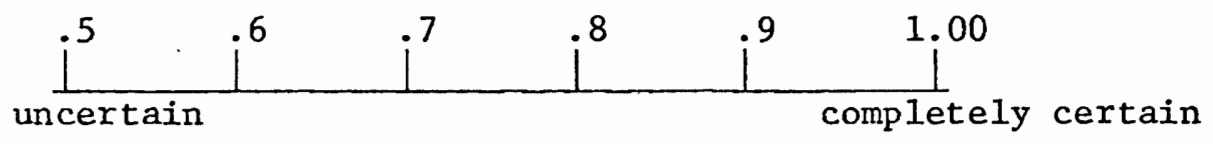

8. PRELIMINARY DECISION: check-box, skip step 9, remove next dot and go on to step 10.

9. FINAL DECISION: check box: $\bar{l}$ and move on to next DECISION SITUATION

10. Are the six samples so far most likely to have come from the (circle your choice) PROFITABLE NON-PROFITABLE SHIPMENT

- indicate certainty on scale:

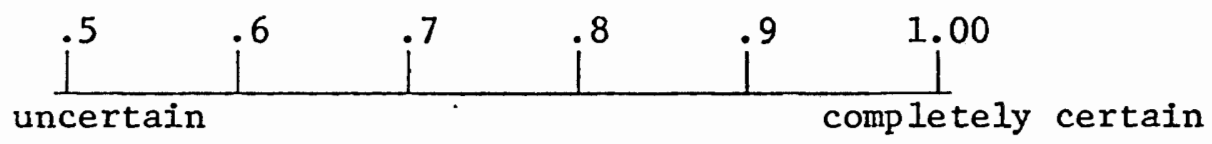

11. PRELIMINARY DECISION: check box, skip step 12, remove next dot and go on to step 13.

12. FINAL DECISION: check box: and move on to next DECISION SITUATION

13. Are the seven samples so far most likely to have come from the (circle your choice) 
-indicate certainty on scale:

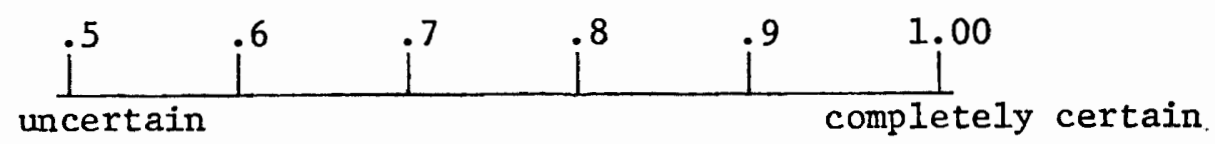

14. PRELIMINARY DECISION: check box, skip step 15, remove next dot and go on to step 16 .

15. FINAL DECISION: check box: $/$ and move on to next DECISION SITUATION

16. Are the eight samples so far most likely to have come from the (circle your choice)

PROFITABLE NON-PROFITABLE SHIPMENT

-indicate certainty on scale

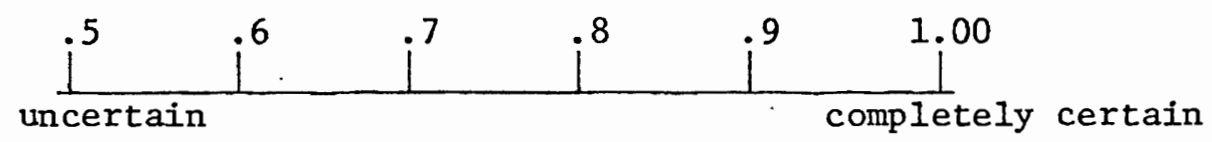

17. PRELIMINARY DECISION: check box, skip step 18, remove next dot, and go on to step 19 .

18. FINAL DECISION: check box: and move on to next DECISION SITUATION.

19. Are the nine samples so far most likely to have come wrom the (citcle. your.choice) PROFITABLE NON-PROFITABLE SHIPMENT

-indicate certainty on scale:

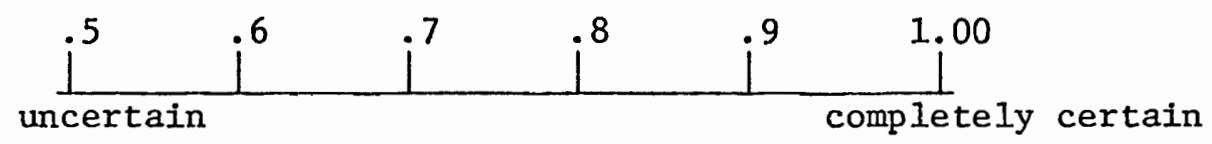

20. PRELIMINARY DECISION: check box, skip step 21, remove next dot, and go on to step 22 .

21. FINAL DECISION: check box: and move on to next DECISION SITUATION. 
22. Are the ten samples so far most likely to have come from the (circle your choice) PROFITABLE NON-PROFITABLE SHIPMENT

-indicate certainty on scale:

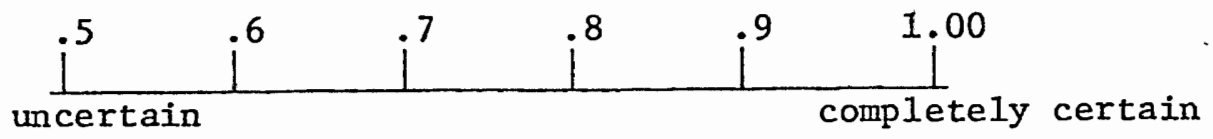

23. PRELIMINARY DECISION: check box:

24. FINAL DECISION: check box: and move on to next DECISION SITUATION. 
APPENDIX B 


\author{
APPENDIX B \\ List of Dogmatism Scale Items That Were \\ Changed to Reflect Non-Sexist \\ Rather Than Sexist Language
}

Item 11: Man on his own is a helpless and miserable creature.

Changed to: A person on his own is a helpless and miserable creature.

Item 25: While I don't like to admit this even to myself, my secret

ambition is to become a great man, like Einstein, or Beethoven, or Shakespeare.

Changed to: While I don't like to admit this even to myself, my secret ambition is to become a great person, like Einstein, or Beethoven, or Shakespeare.

Item 35: In the history of mankind there have probably been just a handful of really great thinkers.

Changed to: In the history of humanity there have probably been just a handful of really great thinkers.

Item 37: A man who does not believe in some great cause has not really lived.

Changed to: A person who does not believe in some great cause has not really lived. 